\title{
دور النسق المعماري كأداة لتصميم واجهات المباني في مصر \\ Architectural pattern role as a tool for design building facades in Egypt
}

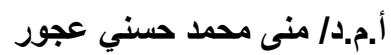

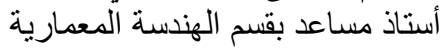 \\ كلية الهندسة بالمطرية - جامعة حلو ان النمان \\ Mona.mhosni@gmail.com
}

\author{
أ. أ.د.د/ ألفت عبد الغنى سليمان حلوه

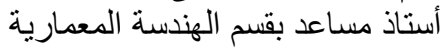 \\ كلية الهندسة بالمطرية - جامعة حلو النئ \\ Olfat_hlwa@yahoo.com
}

ملخص البحث

إن الذي يُميز العمارة ويرفعها إلى مسنوى الفن هي تللك المكونات المنراصة مع بعضها البعض و التي تشكل النسق

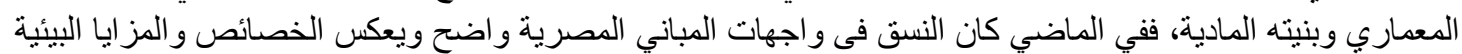

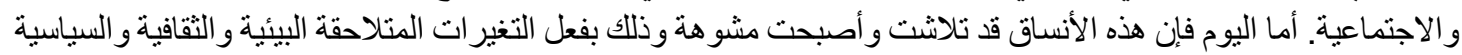
و الاجتماعية، حيث غزت واجهات المباني في معظم المدن المصرية. فكانت النتيجة أن ذابت ملامح ومظاهر الأبر الأنساق

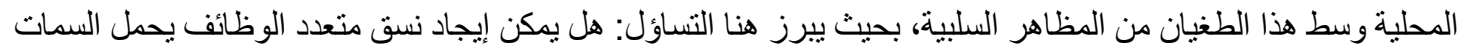

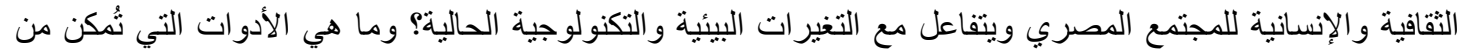

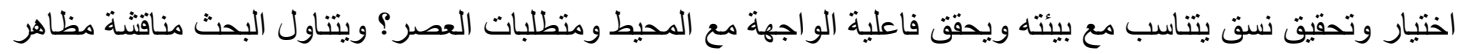

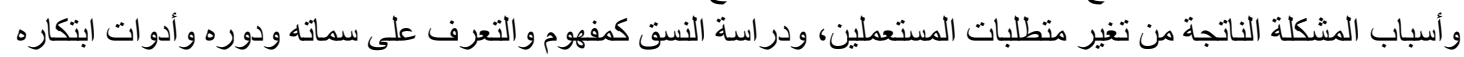
بالتو ازي مع در اسة سمات أنساق بيئات العمارة المصرية، لاستتباط سمات النسية النسق المتو افق المعاصر و اقتر اح كيفية الحلول

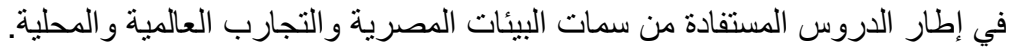

الكلمات المفتاحية: العمارة، النسق، الهندسية، النظام، التصميم البار امتري، جمالي، الانشاء، التوافق البيئي، التقليدي، تكنولوجي، الحوسبة.

ا مقدمة

1/1

يُعاني عدد كبير من واجهات المباني في مصر في العصر الحالي من حالة من التشويه وتداعي الهوية

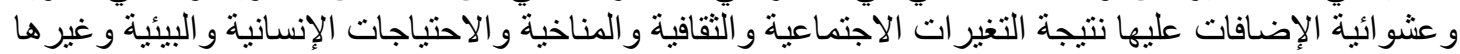

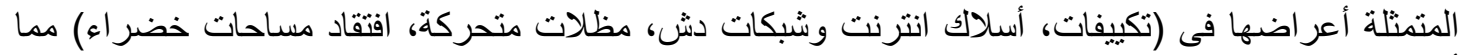
أدي إلى غياب دور النسق المعماري المميز لها والذي من خلاله يمكن ايجاد حلول للتفاعل مع هذه المتغير ات ات التهات

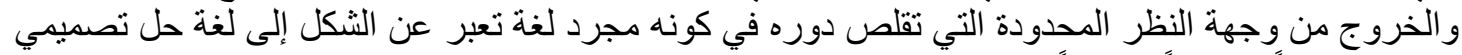

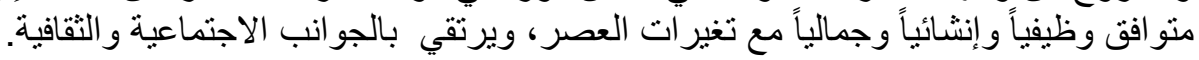

$$
\text { r/ }
$$

• رصد الوضع القائم لنسق بعض الواجهات في مصر و إلقاء الضوء على مظاهر المشكلة.

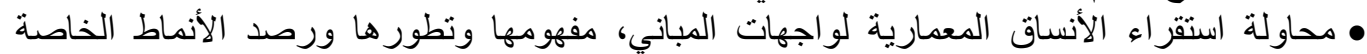

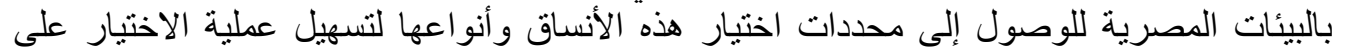
المصمم وللوصول إلى واجهات تتو افق مع متطلبات العصر والتي تشجئ لتهع على تفاعل المبنى مع البيئة المحيطة. • الوصول إلى صياغة وتركيب البدائل المتاحة وسمات نسق متعدد الوظائف ليتلاءم مع مشكلات

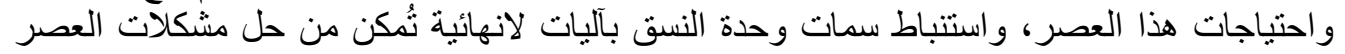
وتلائم جميع محددات التصميح. 


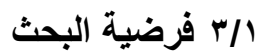

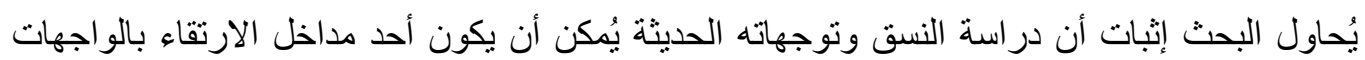

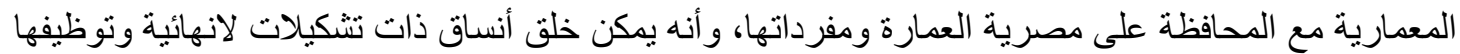
في حل مشكلات العصر في الحالة المصرية.

\section{إء منهجية البحث}

لتحقيق الفرضية يتبع البحث الخطوات البهات التالية:

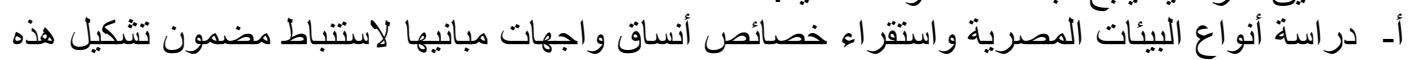

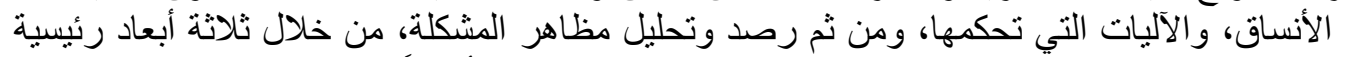

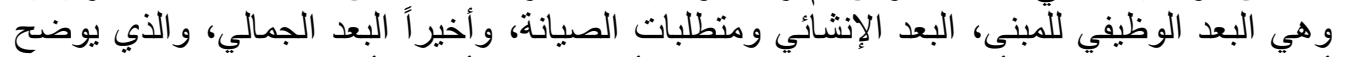

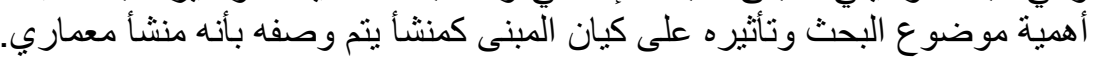

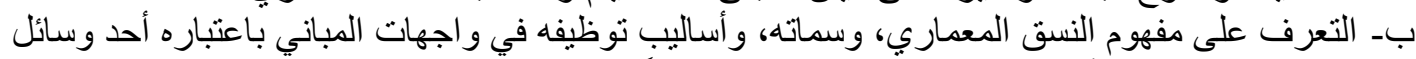

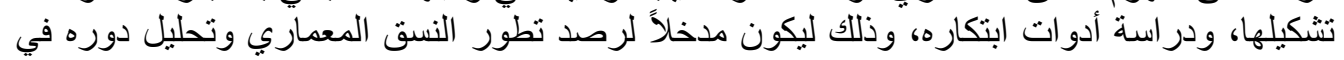

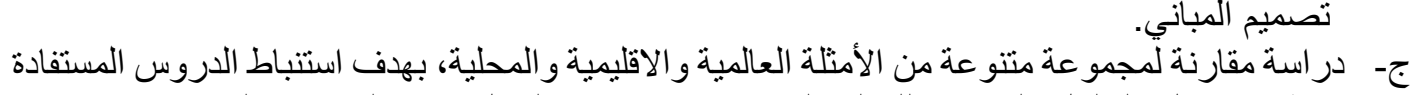

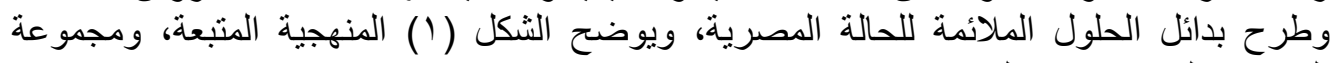
المحددات لتحقيق هدف البحث.

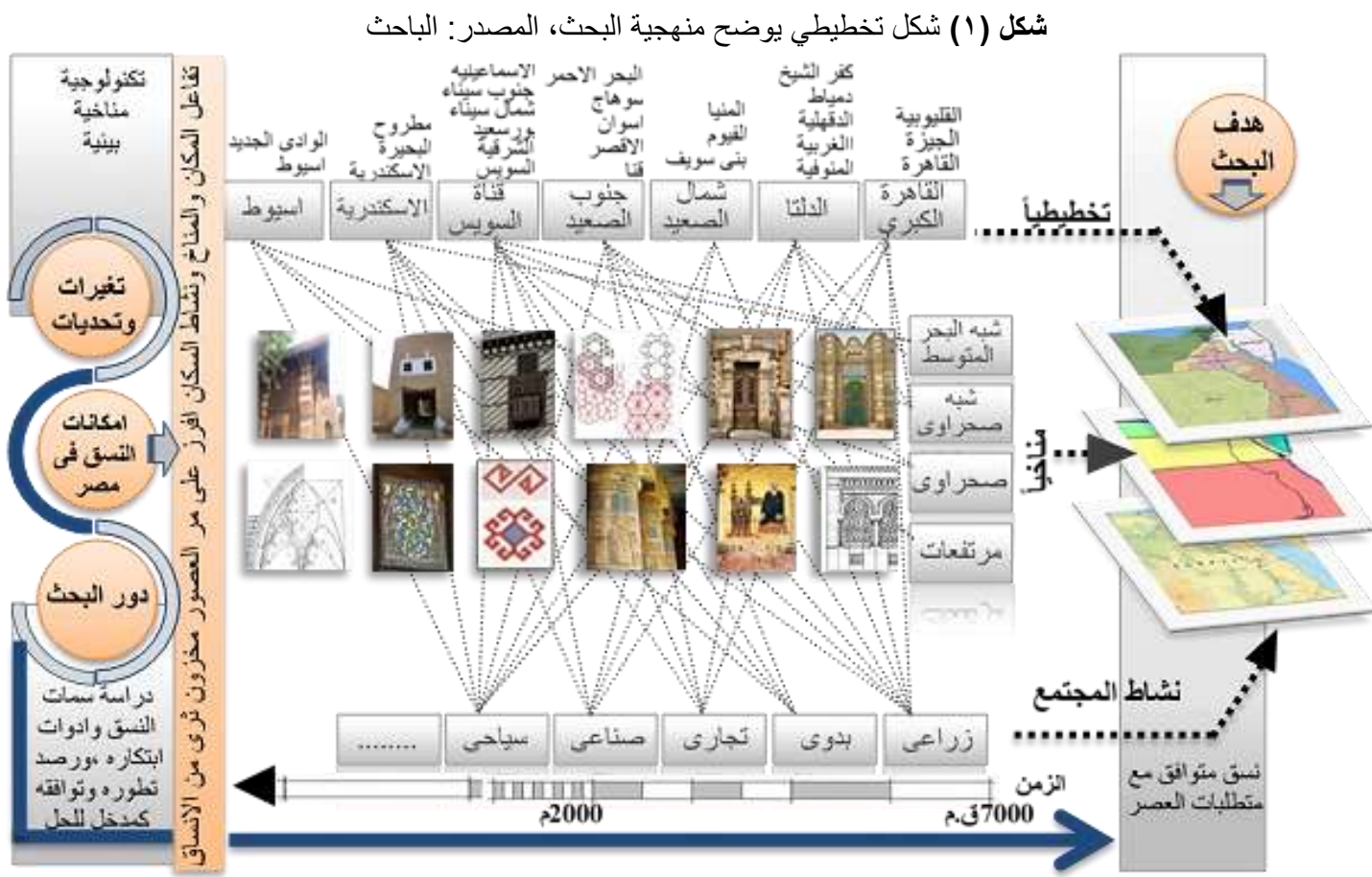

\section{r}

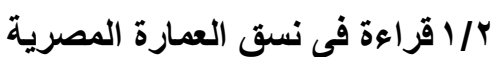

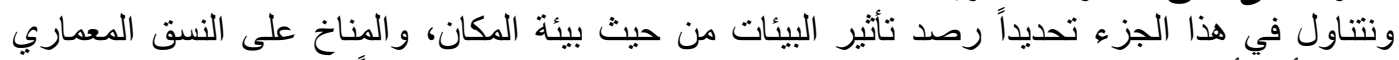

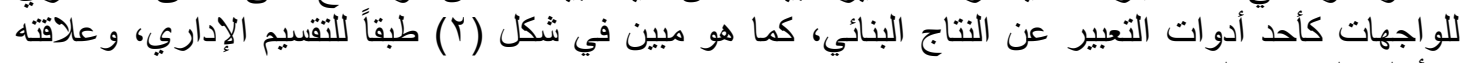
بالأقاليم المناخية المصرية. r/ r تحليل ملامح التغيير الحادث بأنساق الواجهات طبقاً لمتطلبات العصر ـ رصد المشهر الحالي 
شكل (Y) تأثير أنو اع البيئات على النسق المعماري لواجهات العمارة المصرية من حيث الدكان و المناخ وطبقا للتقسيم الاداري،

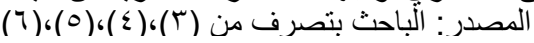

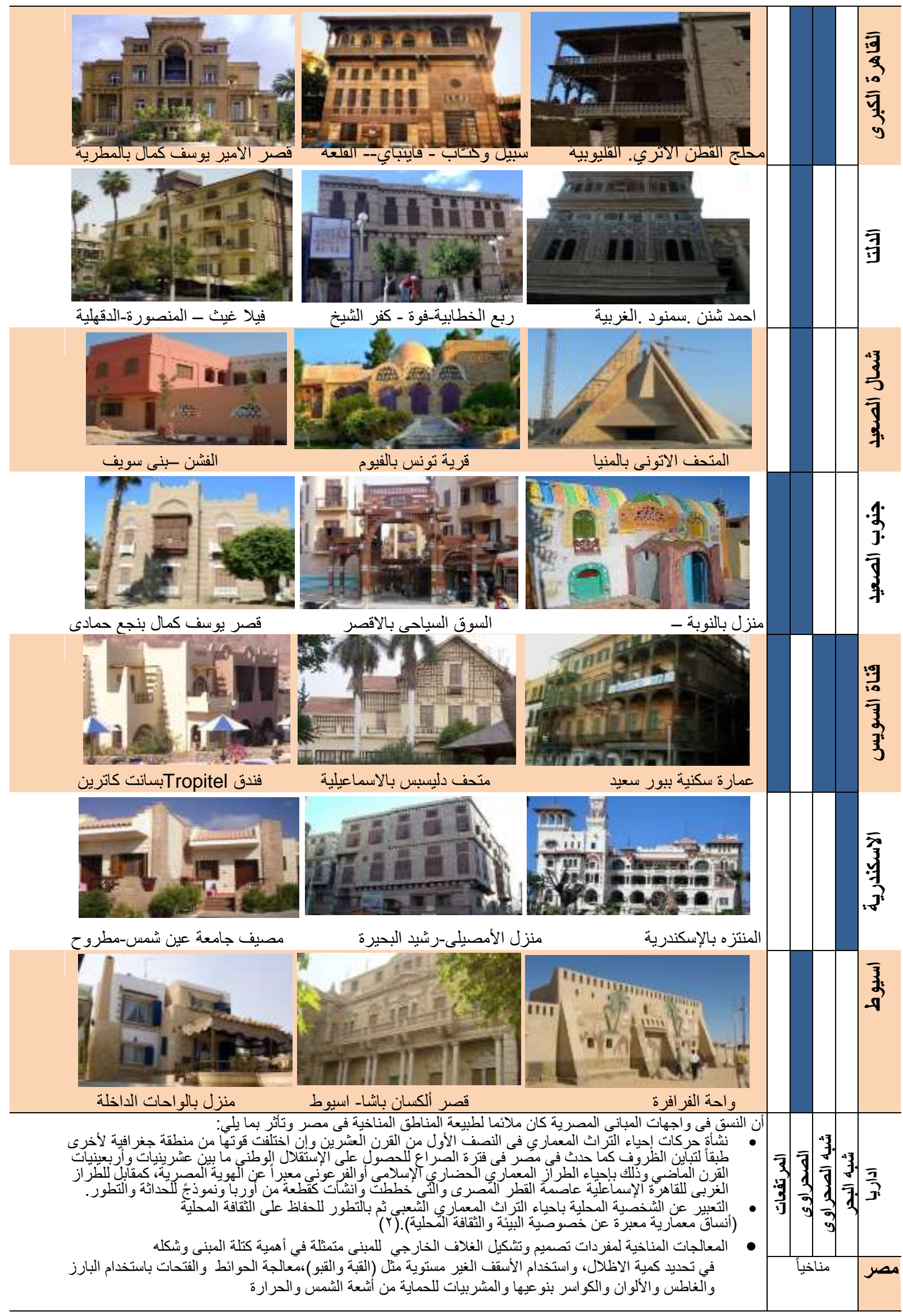




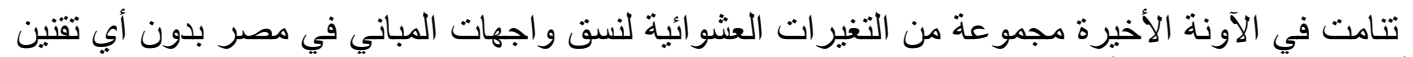

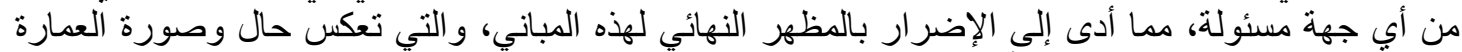

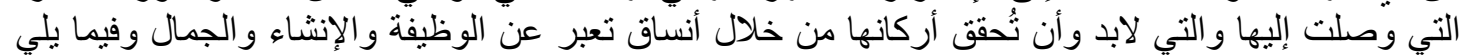

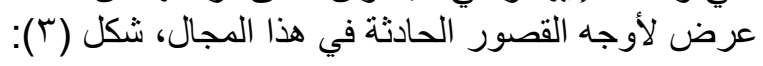

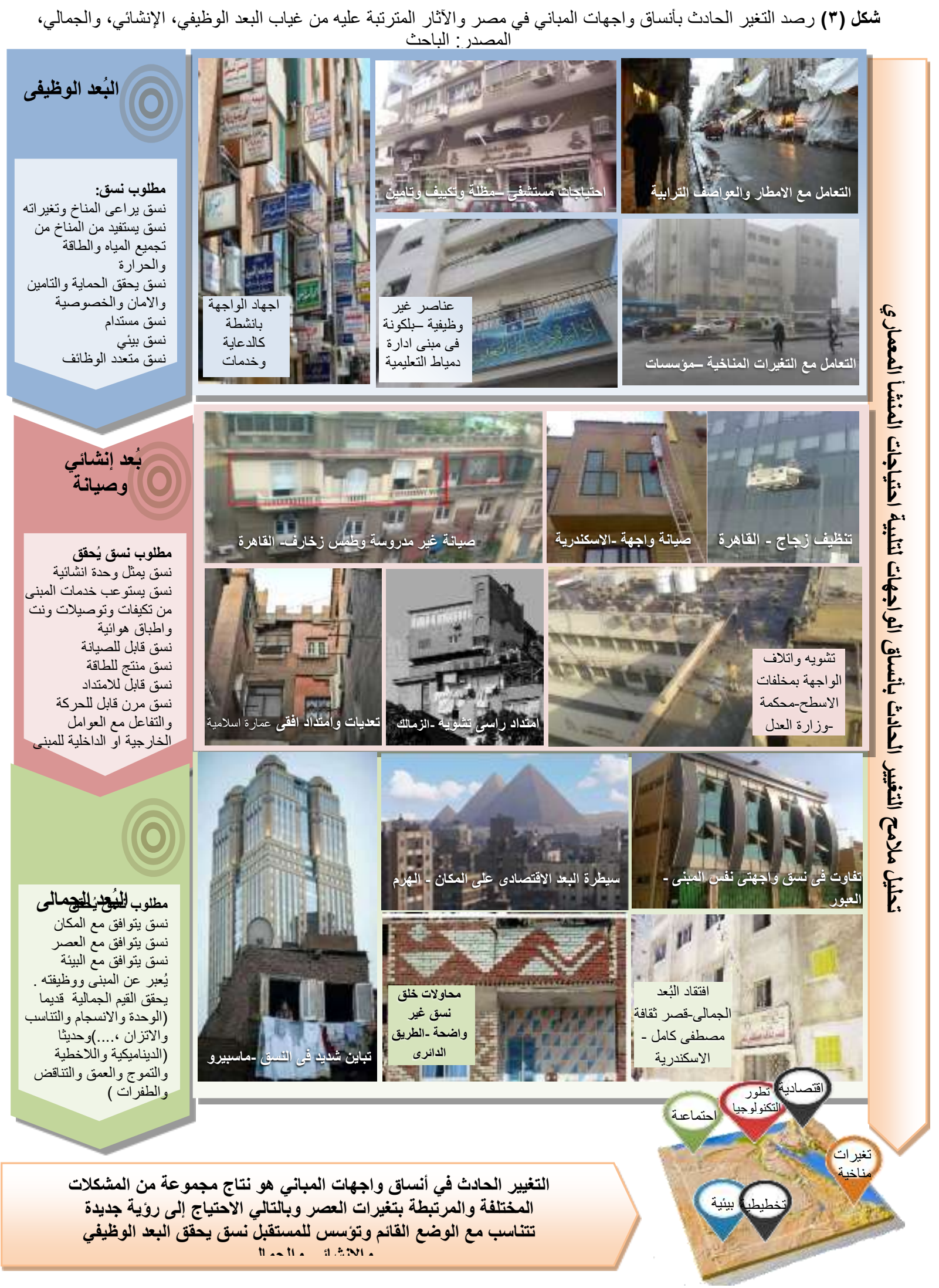




\section{r م ملخل لفهم النسق المعماري في واجهات المباني (السمات ـ الدور ـ أدوات الابتكار)}

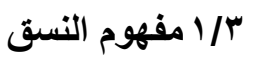

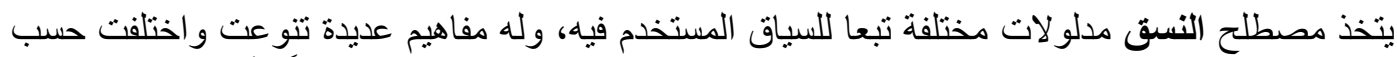

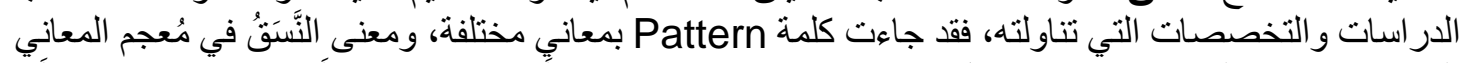

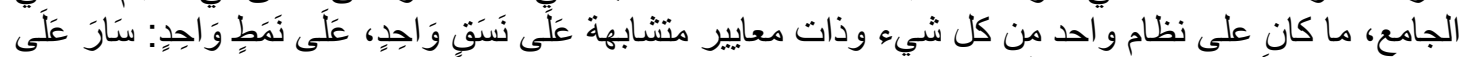

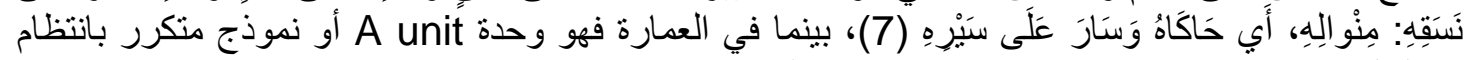

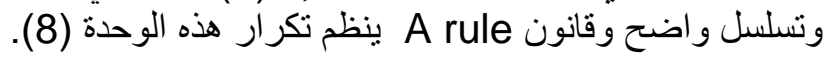

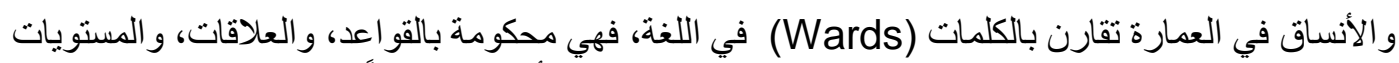

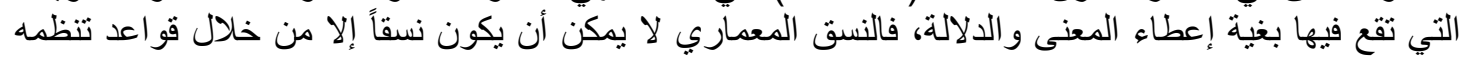

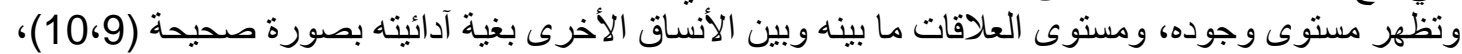

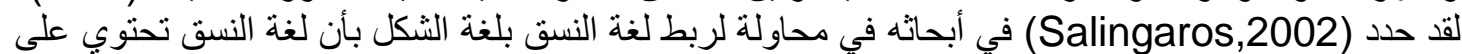

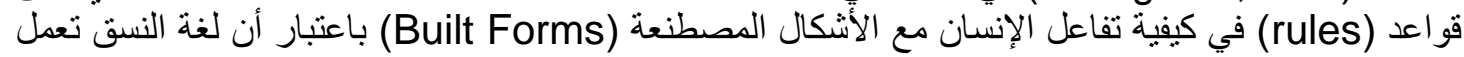

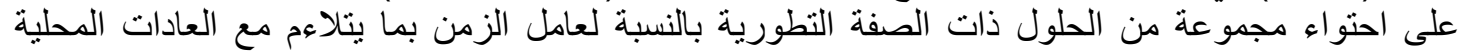
(Custums)

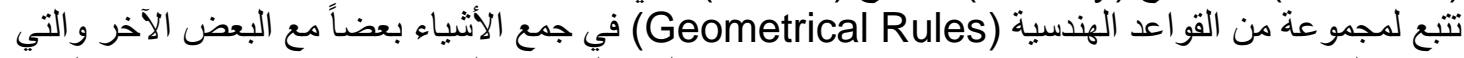

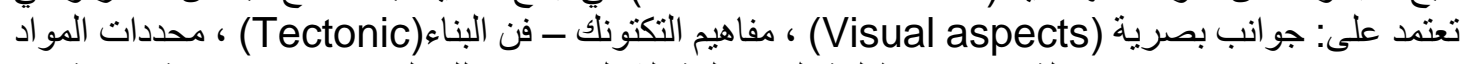
(11)(Materials)

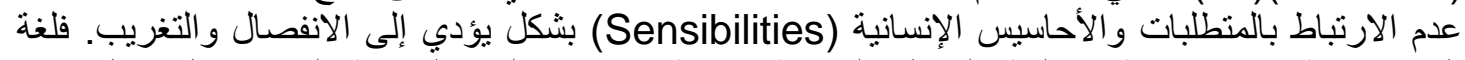

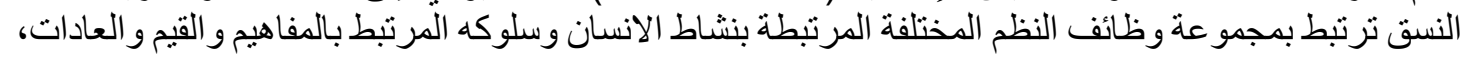

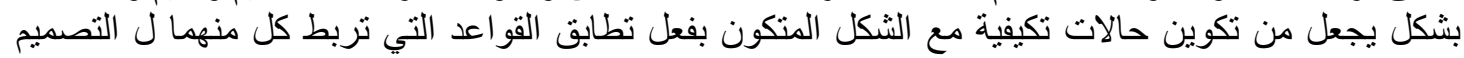

التكيفي(9).

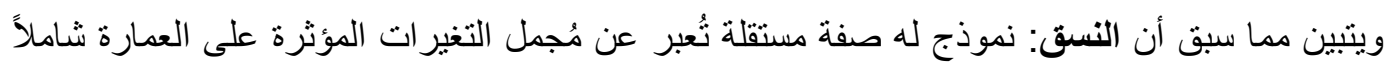

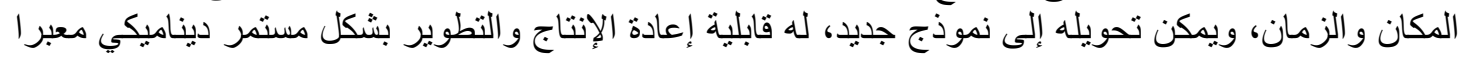

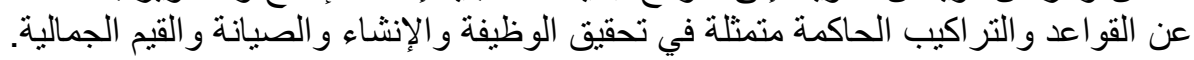

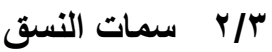

1- المعنى يختلف حسب الزمان و المكان بما بحمله من أفكار، رموز، وصور ذهنية، وطريقة السياق

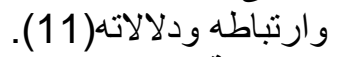

r- التكرارية مثل تكرار تكوينات الأشكال الهندسية ذات المرات المرونة الكافية لتمنح حرية للمعماري لإدخال

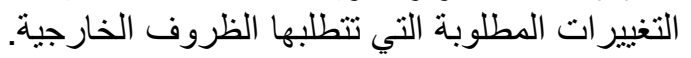

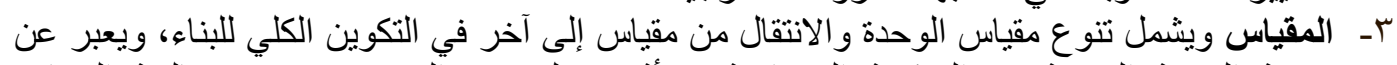

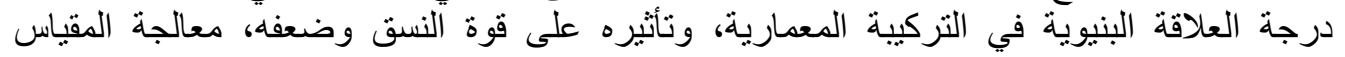

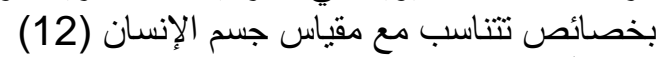

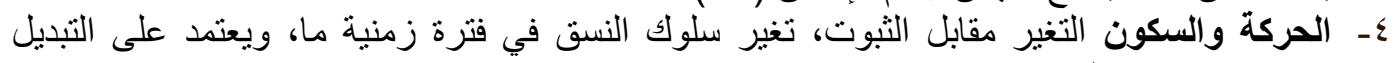

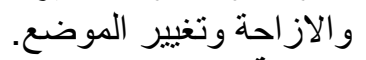

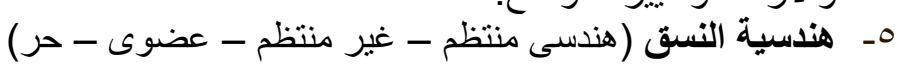

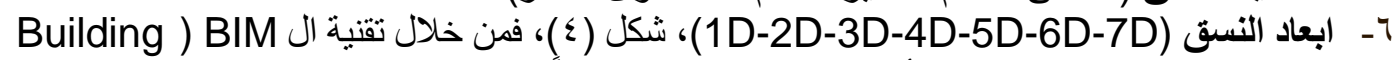

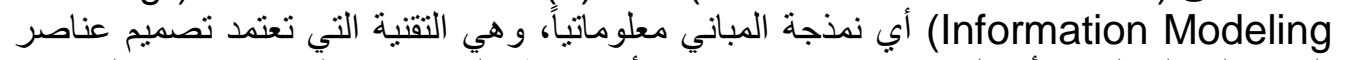

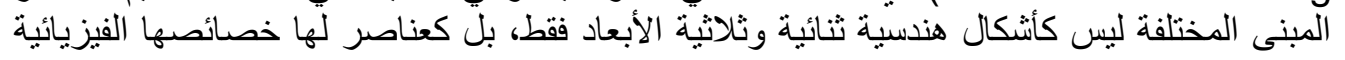

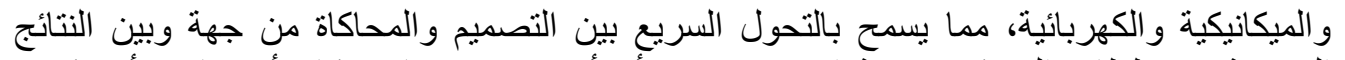

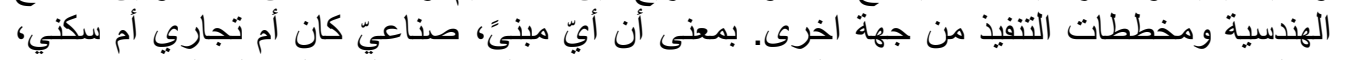

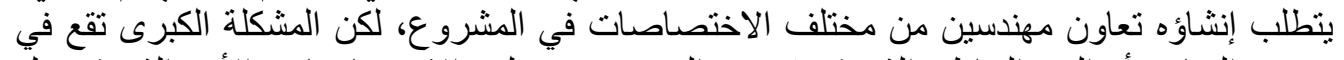

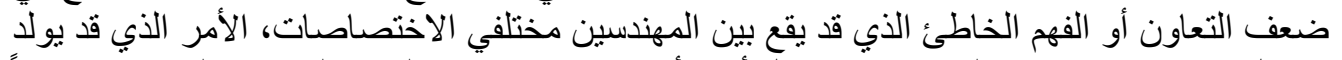

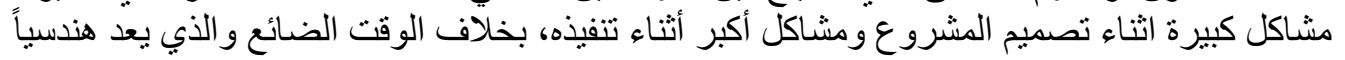


وبالتالي فإن هذه التقنية تجمع بين برامج ال CAD أب الرسم الحاسوبي، وبين برامج المحاكاة Simulation

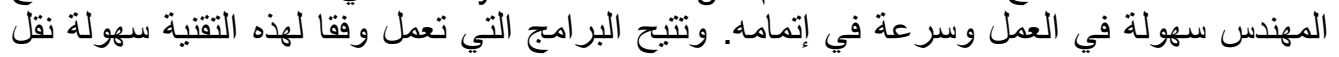

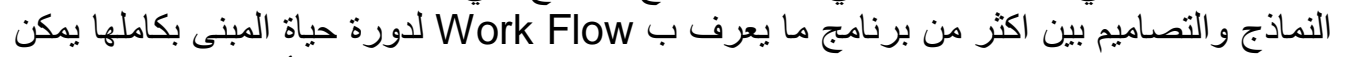

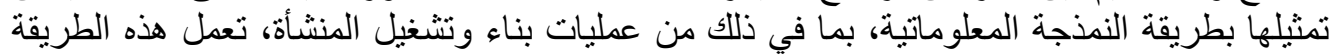

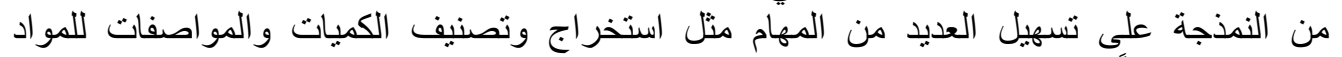

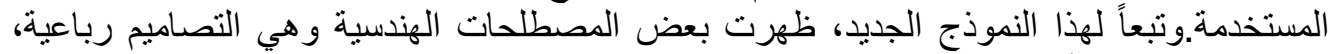

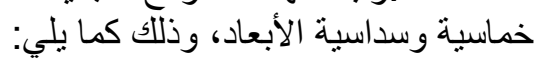

الابعاد، 1D

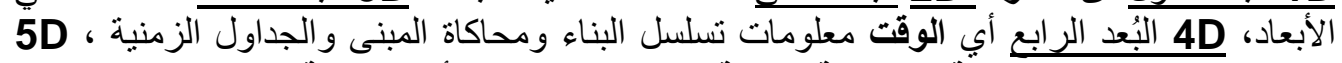

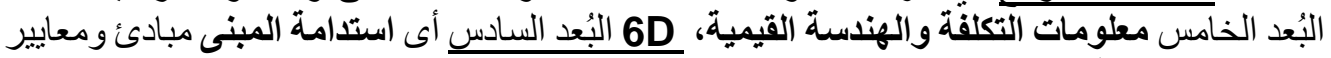

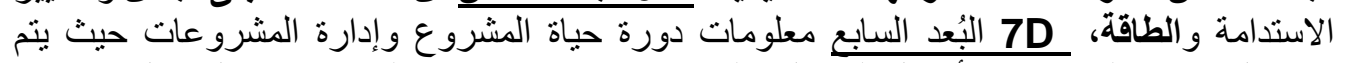

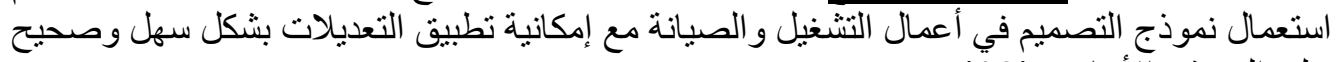

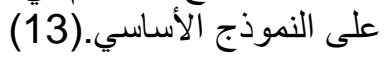
r/r

عرف فيتروفيوس العمارة على أساس أنها تعتمد على الترتيب و التنظيم و الإنسجام و الملائمة و الاقتصادي،

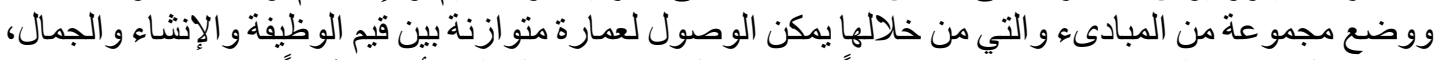

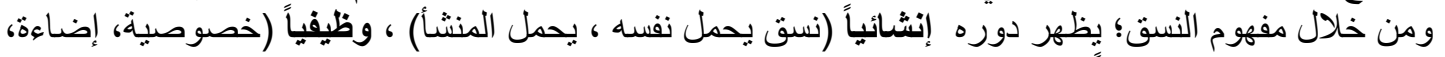

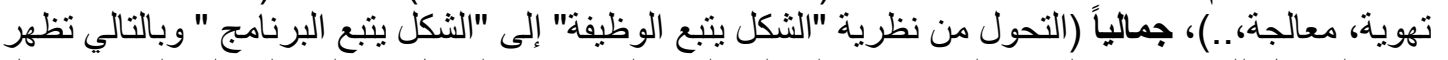

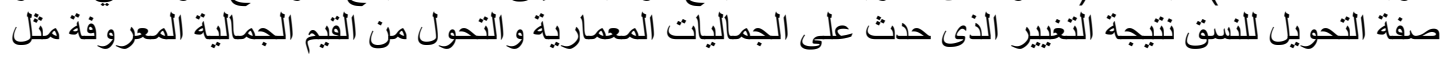

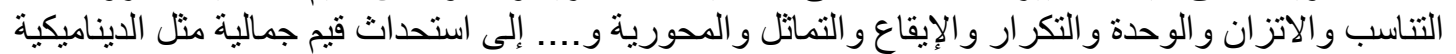

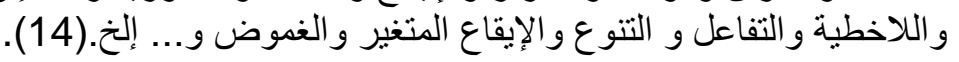




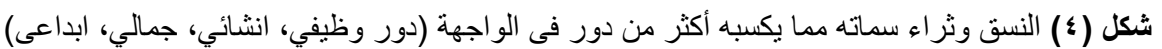

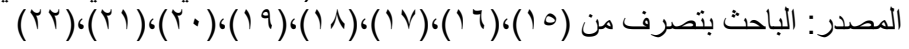

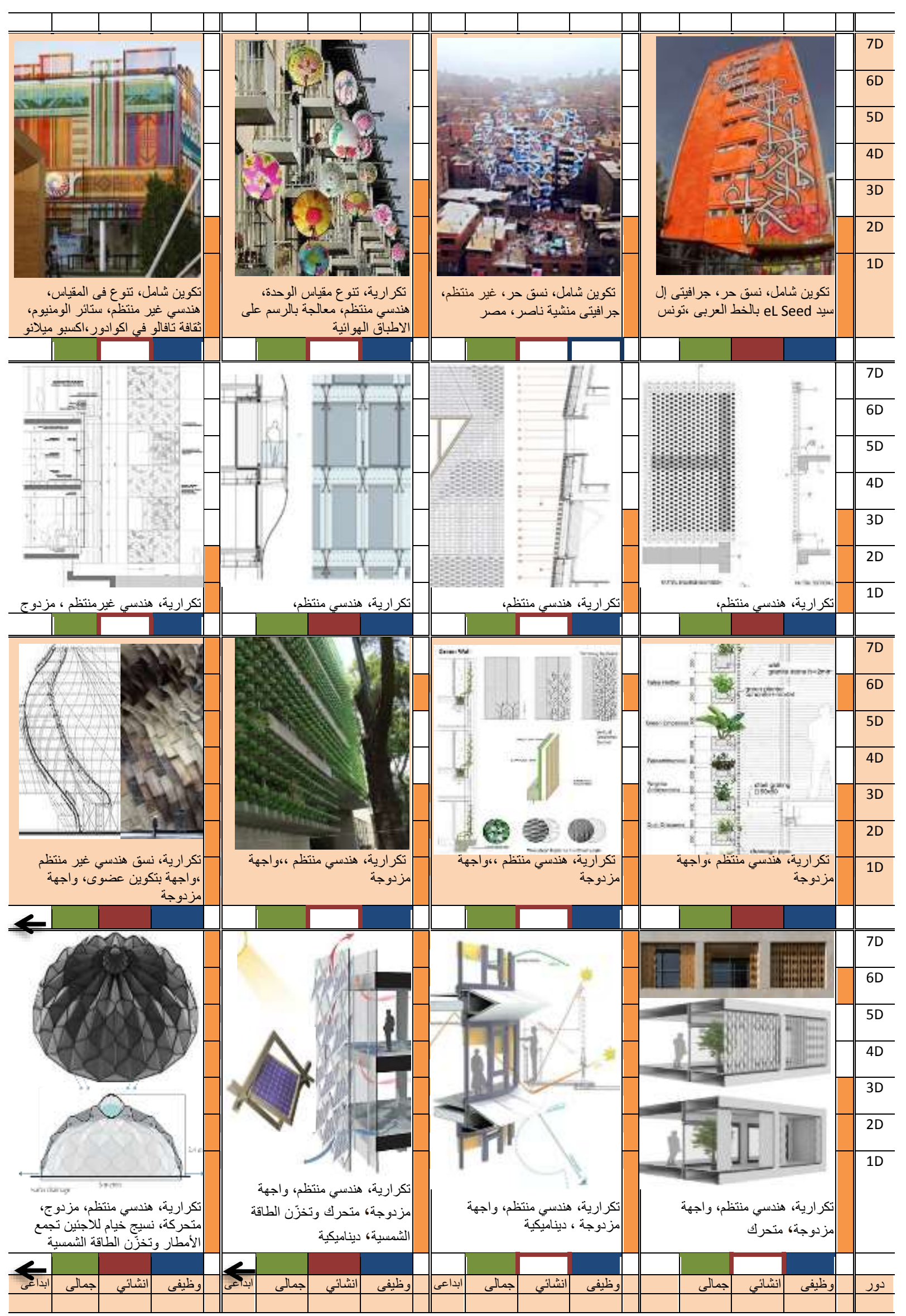




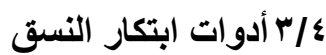

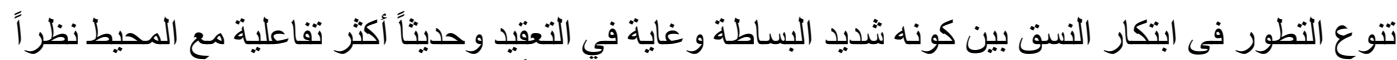

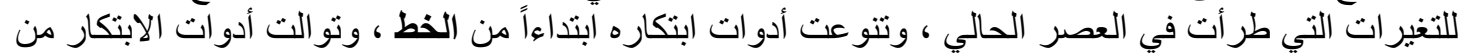

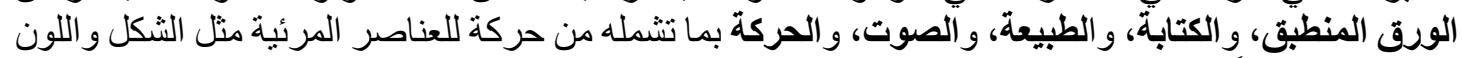

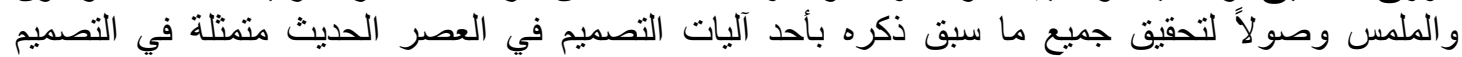

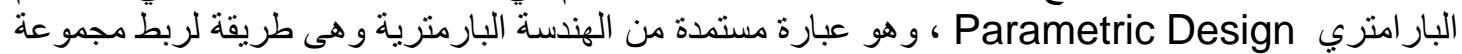

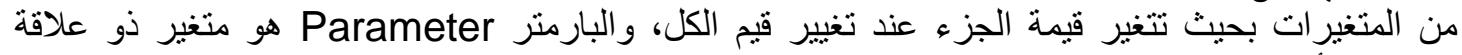

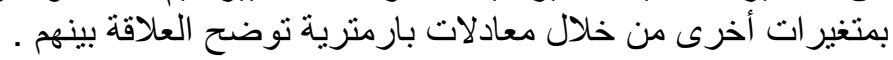

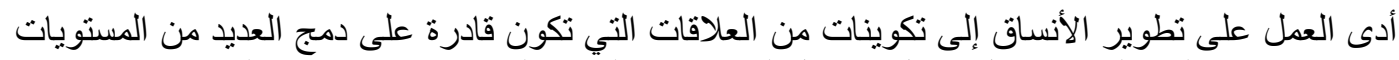

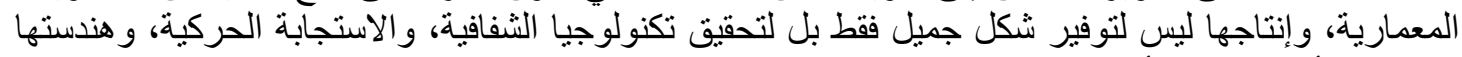

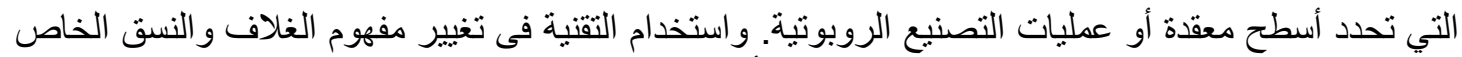

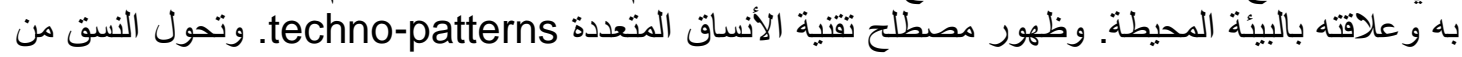

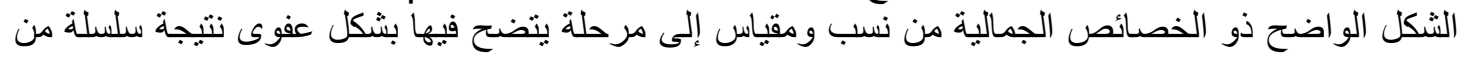

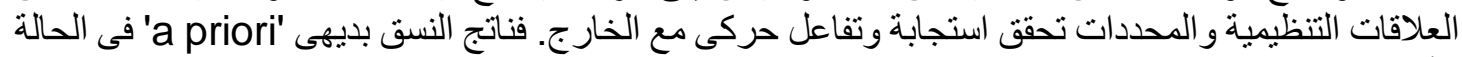

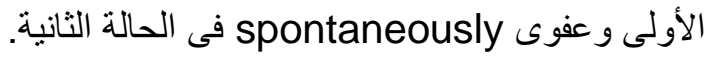

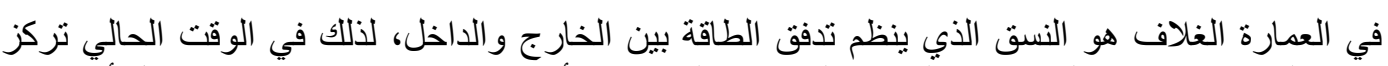

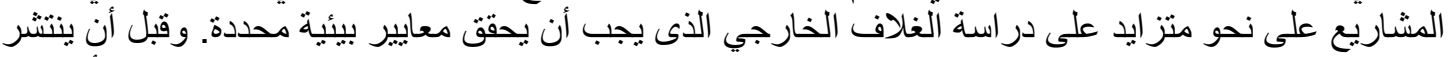

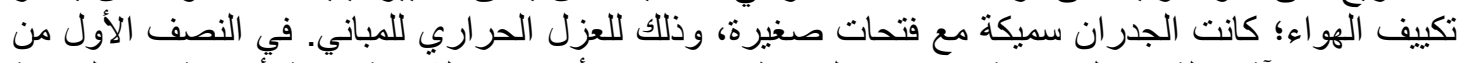

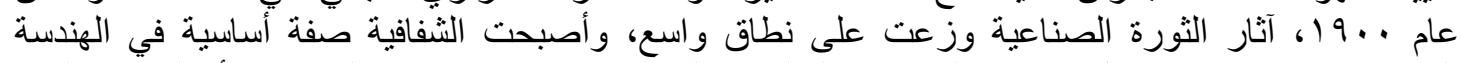

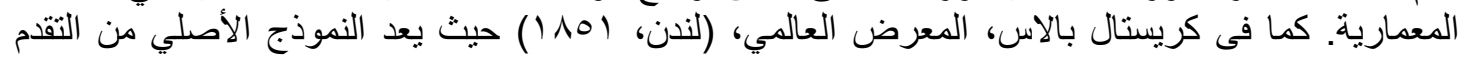

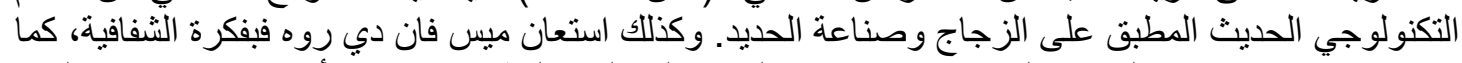

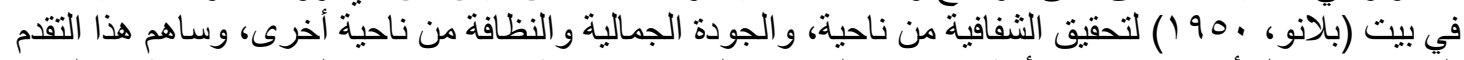

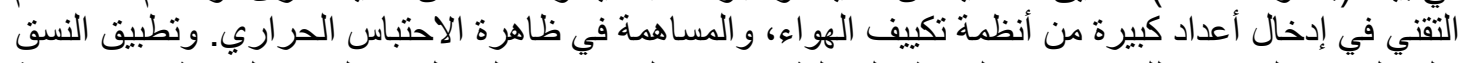

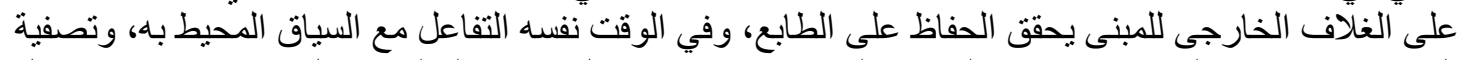

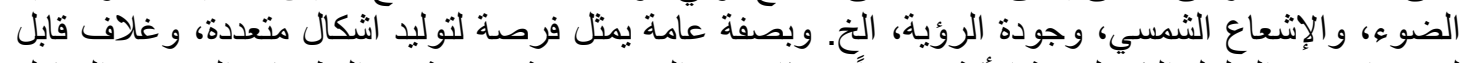

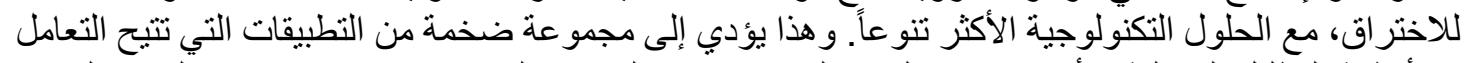

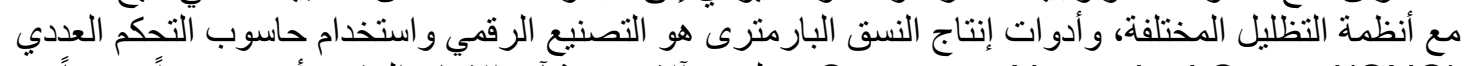
Computer Numerical Control(CNC) كل من إدارة حسابات المشروع واستخدام وتصنيع هندستها المعقدة. ويشمل الإت العديد من الجو النب التي ينبخي النظر

ـ اعداد بدائل المشروع وفقا لترشيدها المكن و البناء الرقمي مثل مثل إعادة التكوين وتقريب السطح.

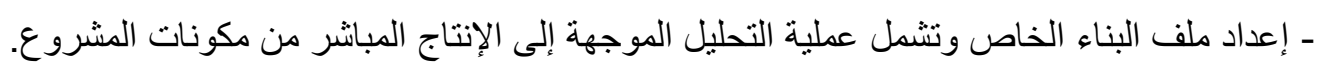
و هنالك نو عان من عمليات التصنيع الرقمي من حيث طريقة التي يتم بها التعامل مع المو اد:

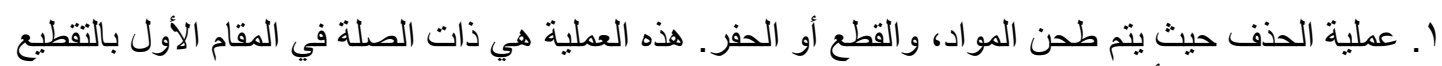

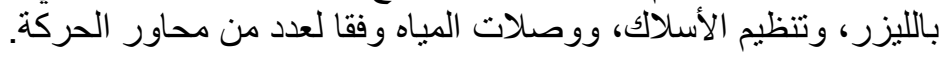

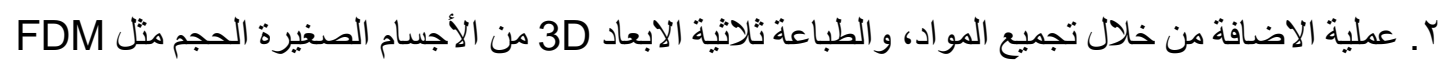

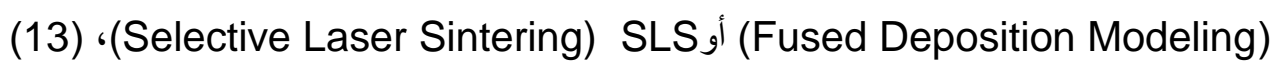

ومن أثهر تطبيقات وبرامج التصميم البرامترى رينو Rhino3D، جروث هوبر ثثلاثى الابعاد Gadybug للنديبياج Lasshopper 3D

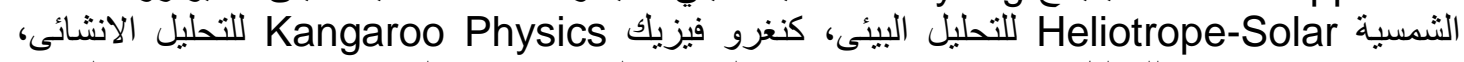

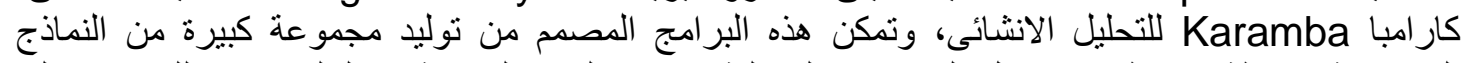

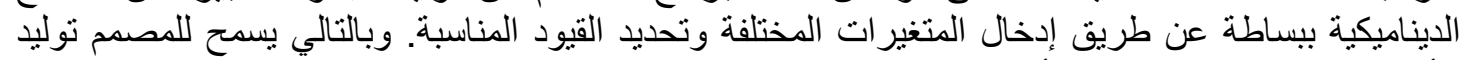

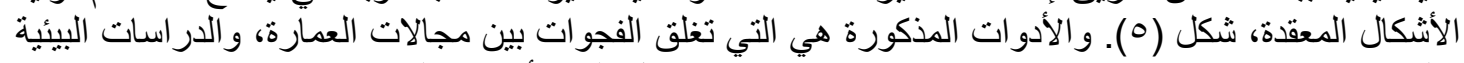

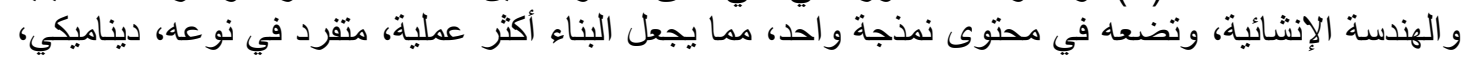

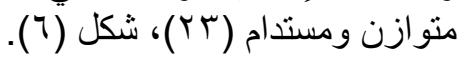




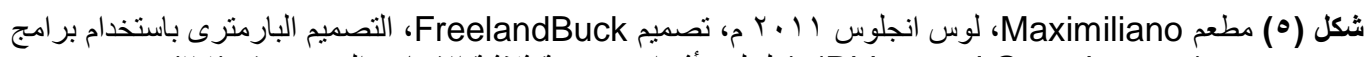
( لخلق تأثير ات بصرية ثلاثية الابعاد ، المرجع رقح (ع) (Rhino and Grasshopper)
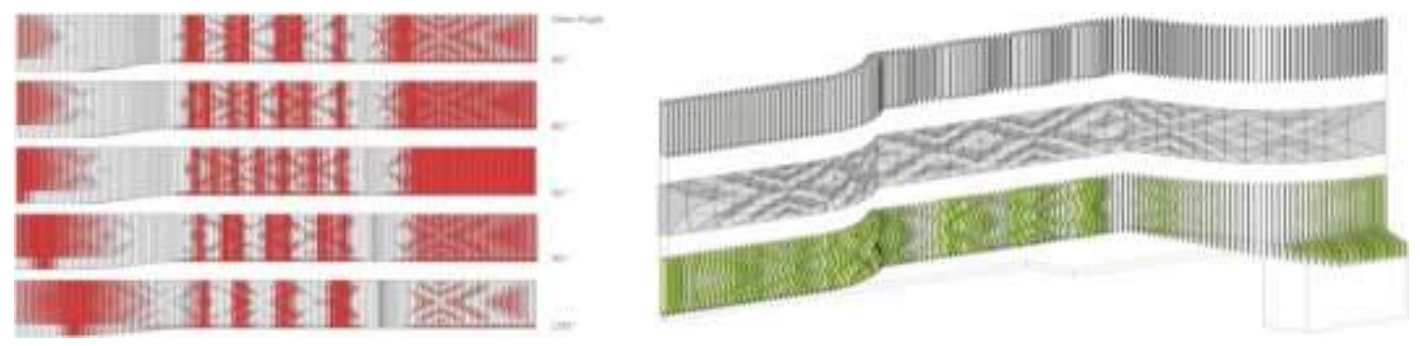

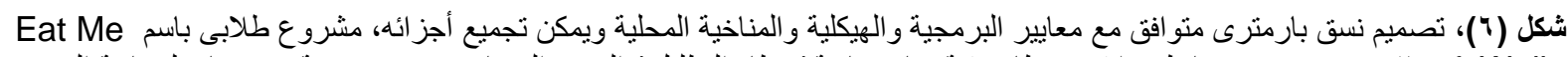

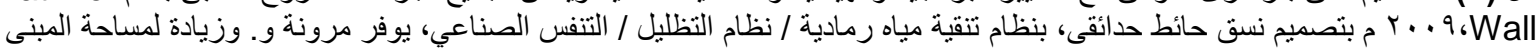

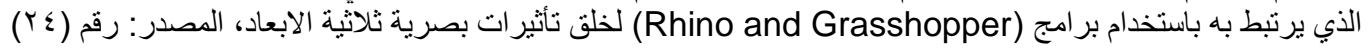

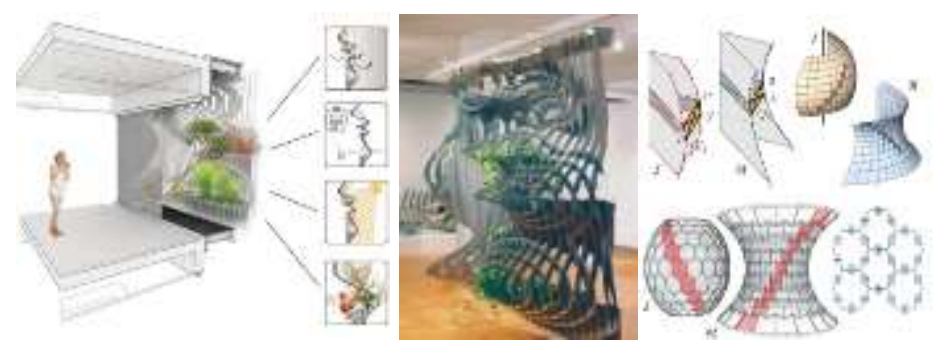

وفيما يلي عرض لبعض تطبيقات أدوات ابتكار النسق:

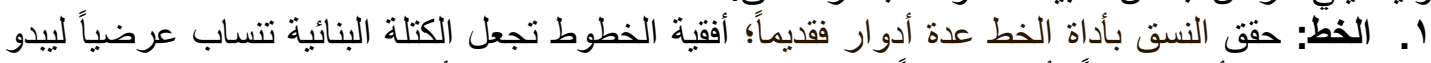

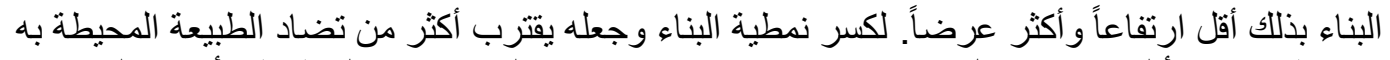

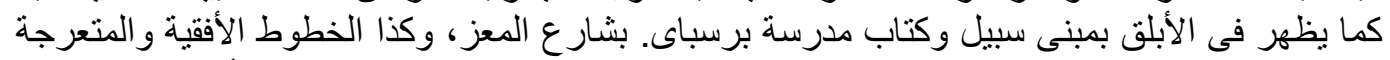

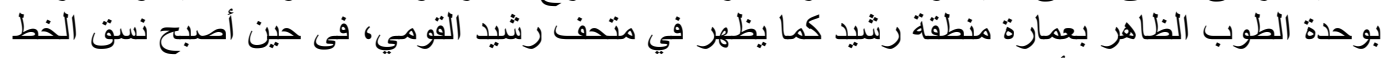

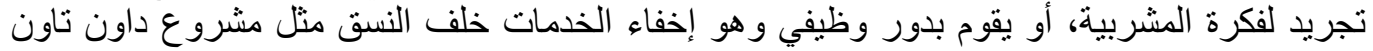
Downtowen

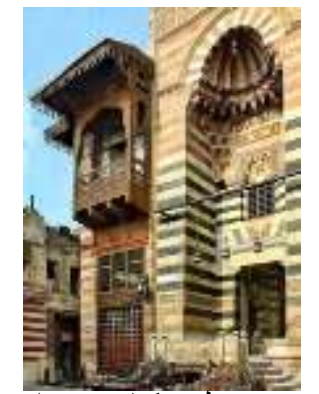

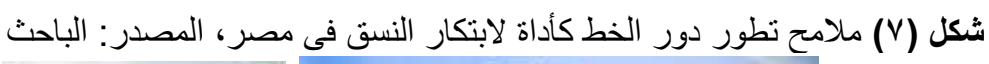
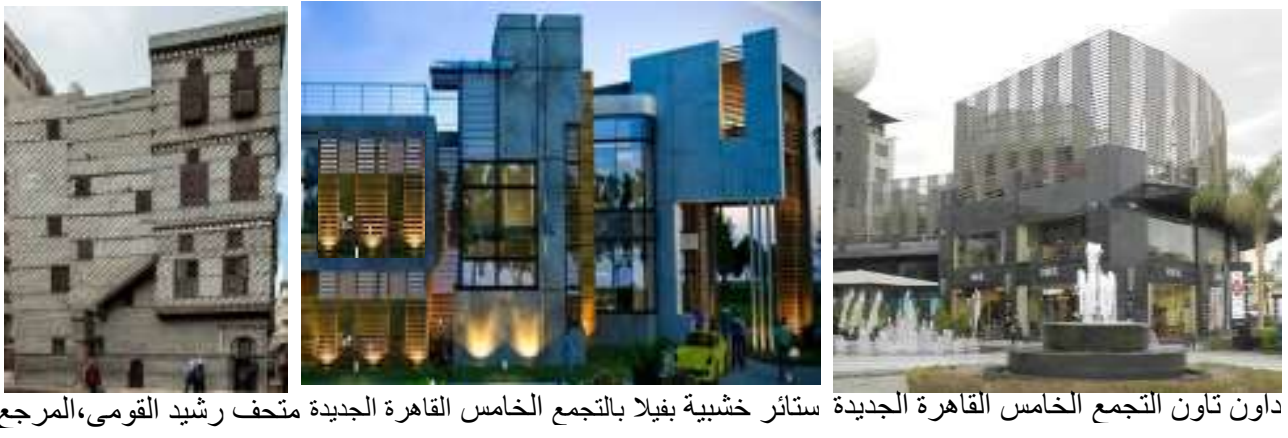

r. الورق المنطبق: لغة طى الورق The language of paper fold أو أنشكال الأوريجامي Origami

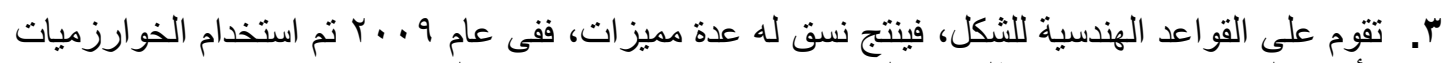

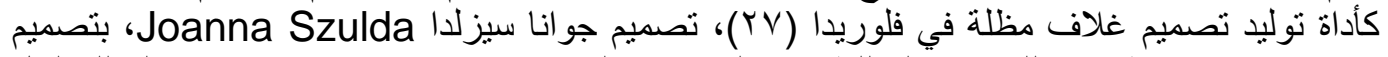

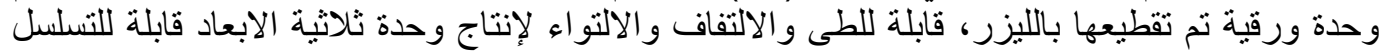

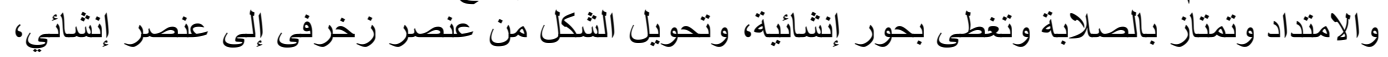

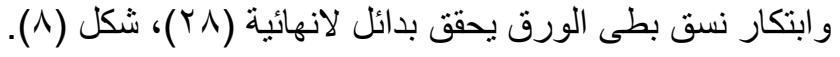

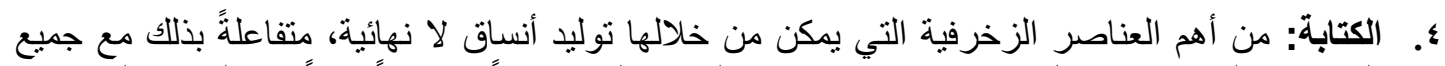

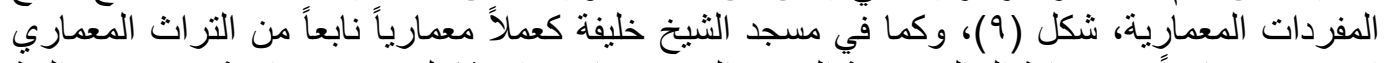
الإسلامي، جامعاً بين عر اقة التقاليد وتقنية العصر الحديث، باستخدام تشكيل هندسي خاصة في تصميم القبة التِّة 
المكونة من نسق كتابات تحمل نقوشاً تبرز رونق الخط العربي وجمالياته، بطراز يحاكي الطراز الأموي (لإني

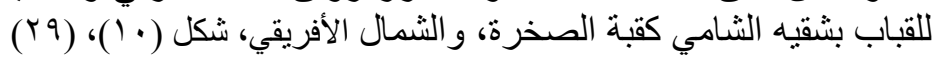

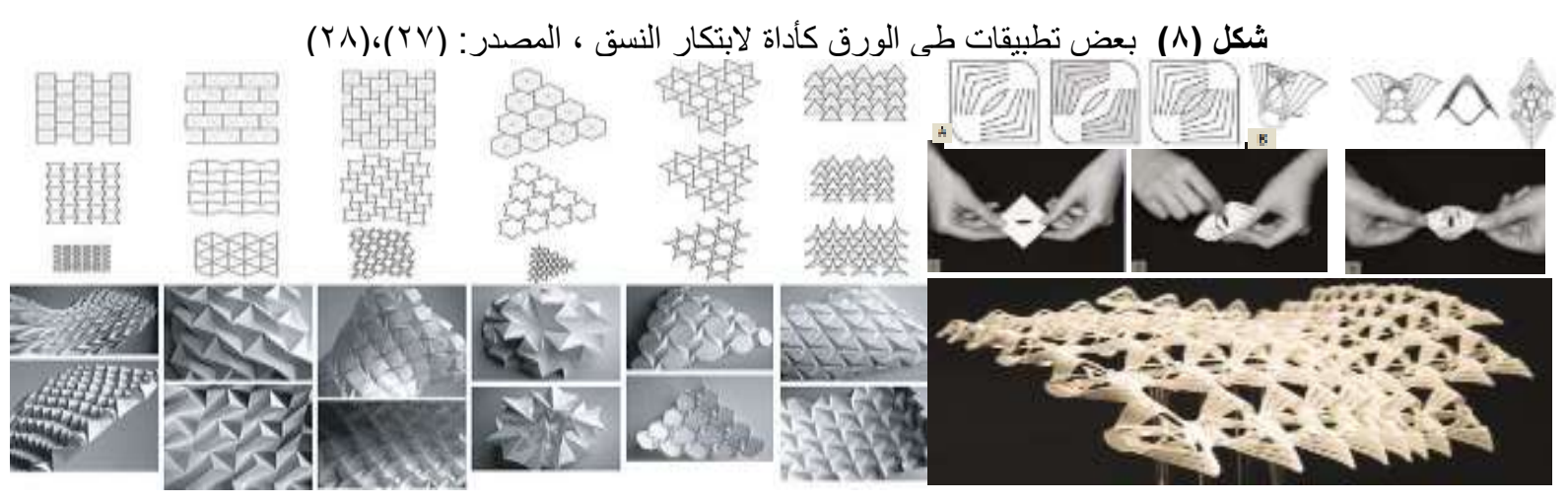

شكل (9) يوضح الكتابة على مختلف العصور فى مصر، المصدر : الباحث
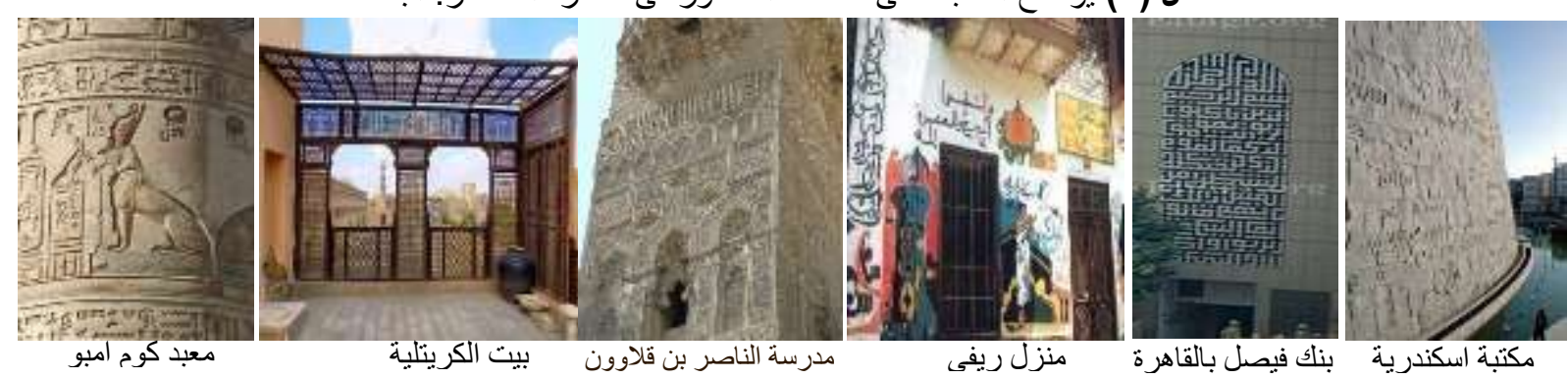

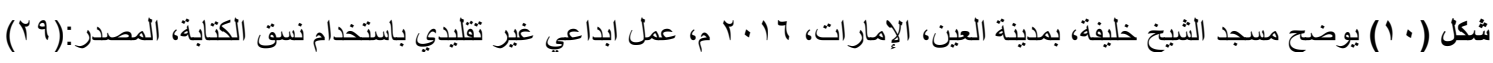
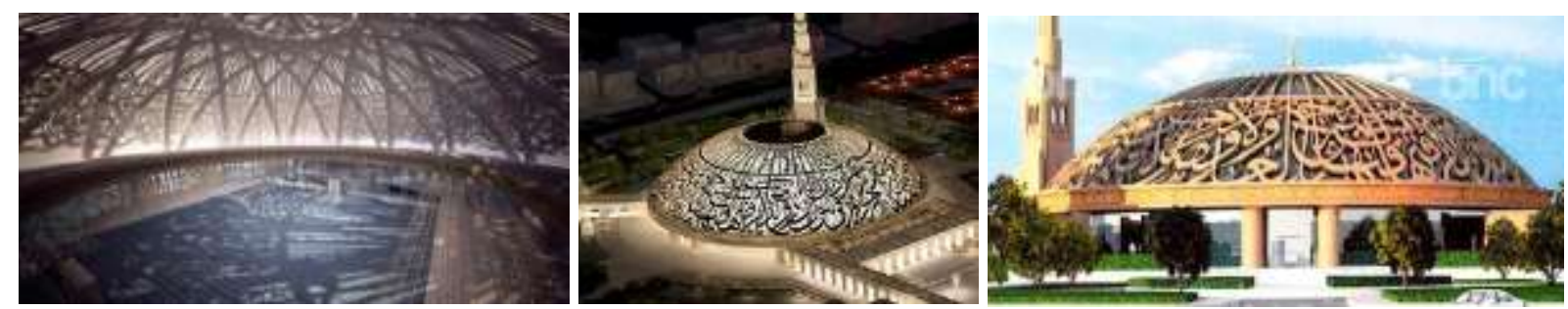

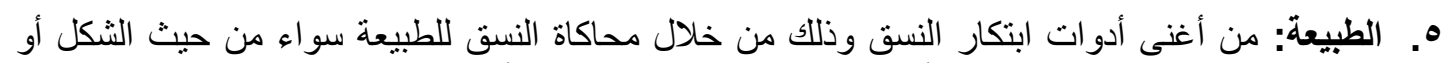

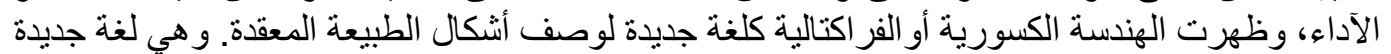

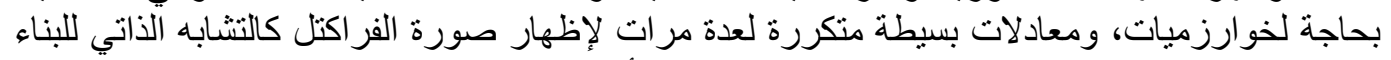

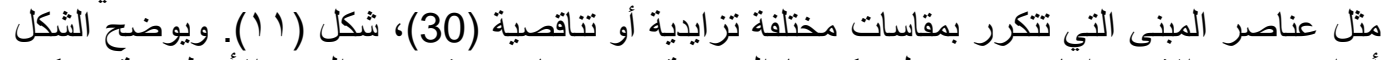

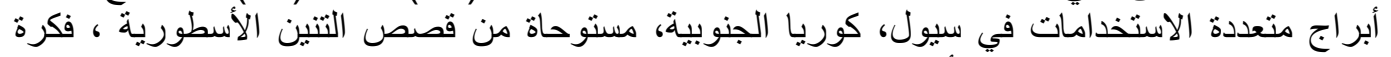

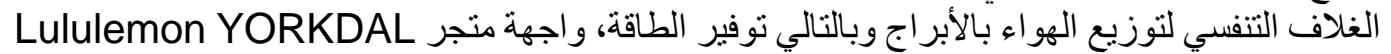

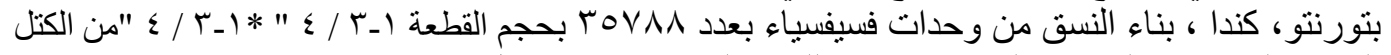

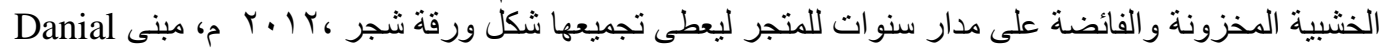


شكل (' (1) يوضح نماذج مختلفة للأنساق المسوحاة من الطبيعة سواء شكلاً أو آداءً، الدصدر : (31)،(32)،(33)،(34)

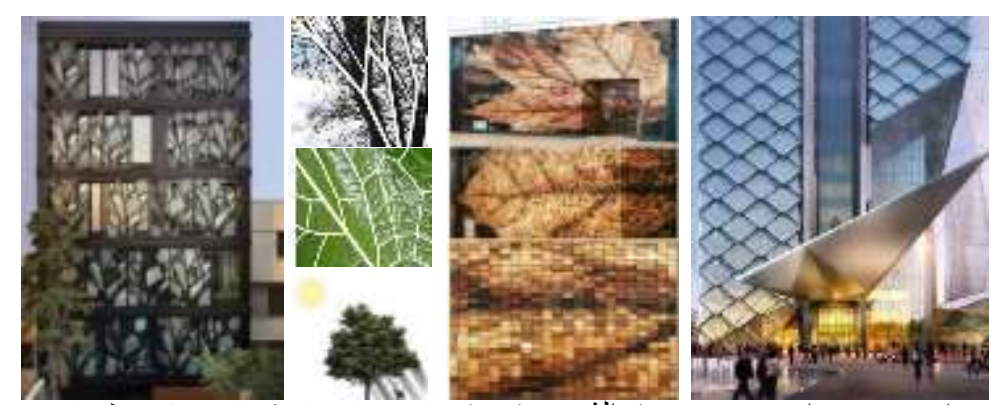

جلد تنين سيول- كوريا ورق الثجر-تورنتو الاغصان و الاشجار -سكن بطهر ان

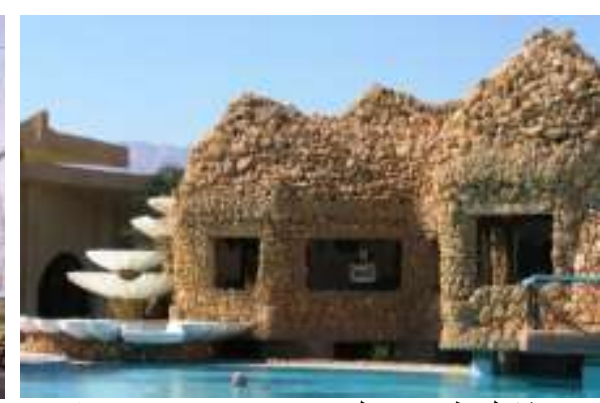

تشكيل طبيعى جبلى- منتجع فى نوبيع - سيناء

السكنى بطهران ،إيران r Y ب r، وتثكيل الواجهة بنسق الأشجار والأغصان كتعبير عن الحدائق و افتقاد

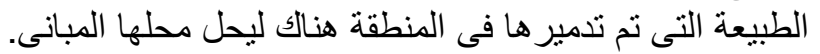

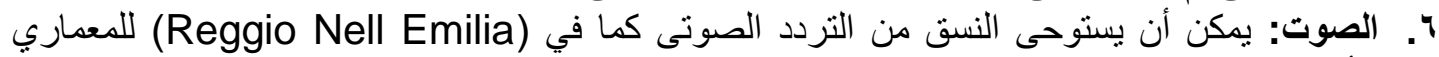

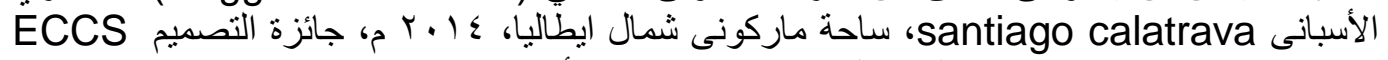

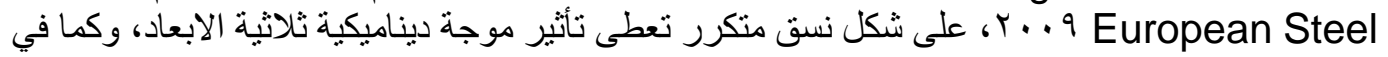

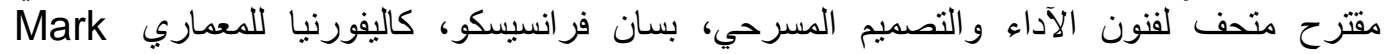
Dziewulski

شكل (r ( ) يوضح نماذج مختلفة للانساق المبتكرة من التردد الصوتي، المصدر : (35)‘(36)
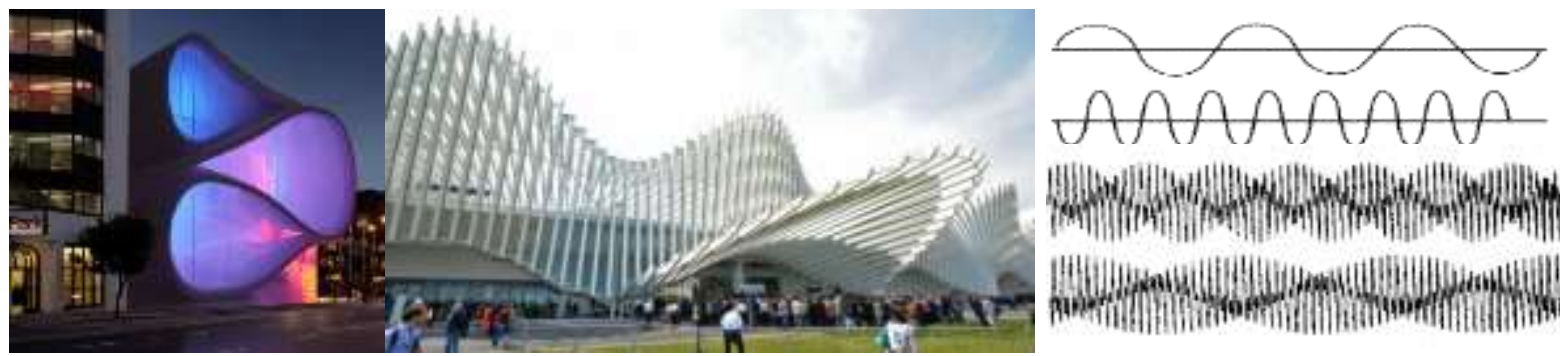

تأثر موجة ديناميكية ثلاثية الأبعاد ، محطة ريجيو نيل إيميليا، ساحة ماركونى شمال ايطاليا ايقاع موسيقي، متحف لفنون المسرح، كاليفورنيا

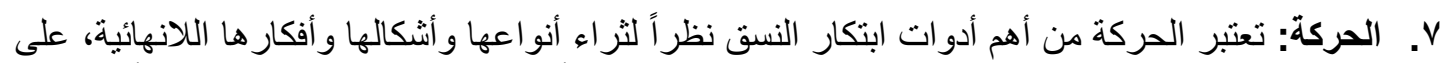

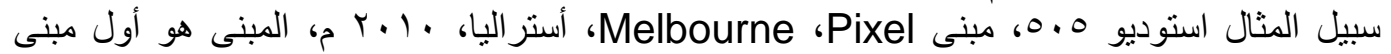

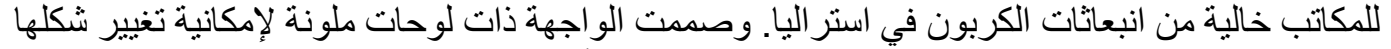

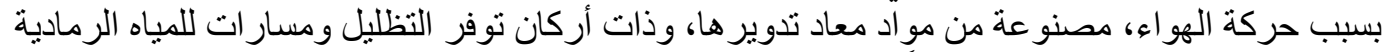

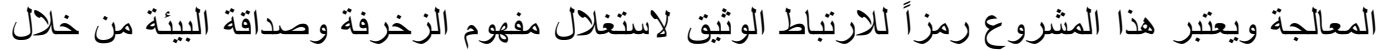

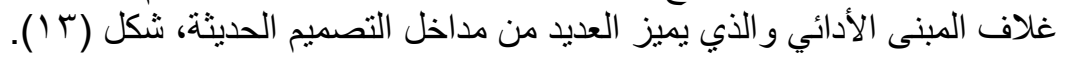

شكل (ب ا ) يوضح وحدة النسق وبدائل حركتها الحلزونية والتي تمثل أحد أشكال الحركة وأحد تطبيقاتها، المصدر : (37)،(38)
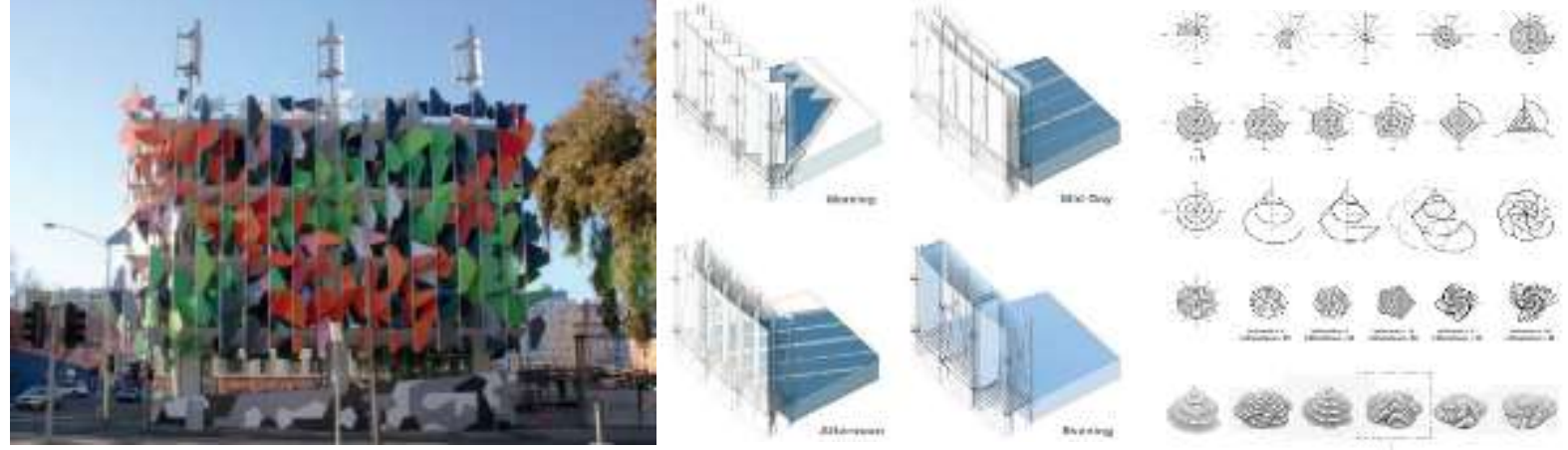

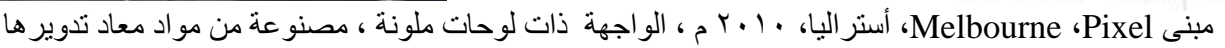


؛ تصليل مقارن لتطور النسق المعماري كأداة لتصميم واجهات المباني

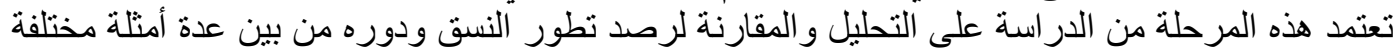

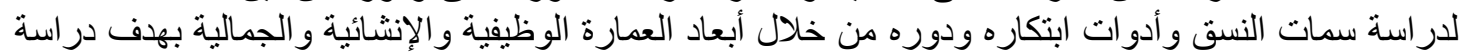

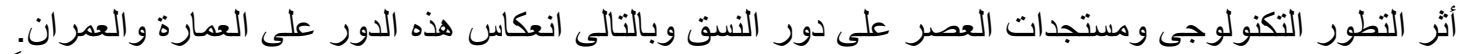

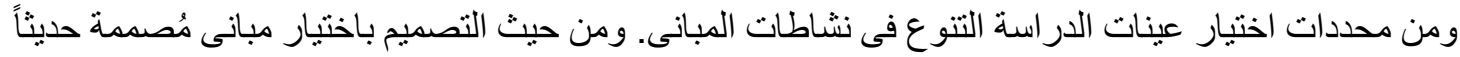

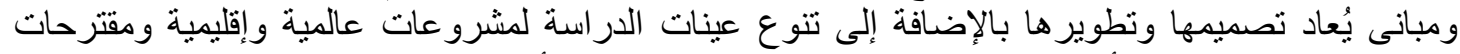

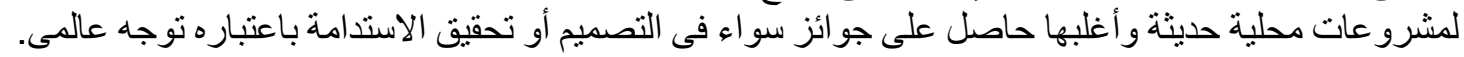

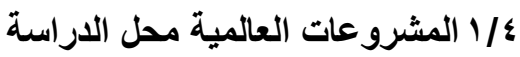

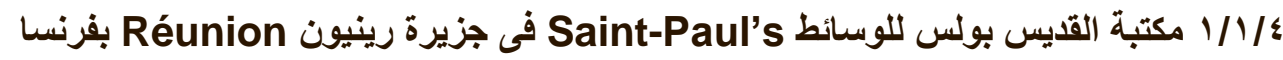

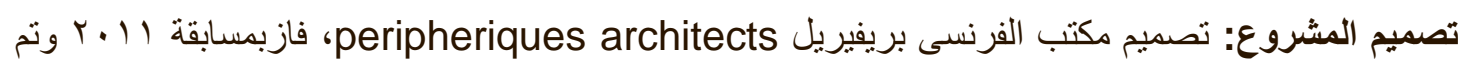

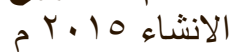

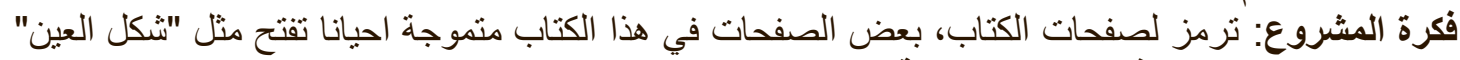

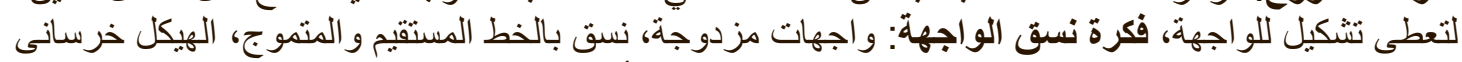

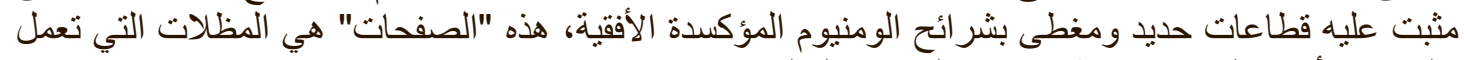

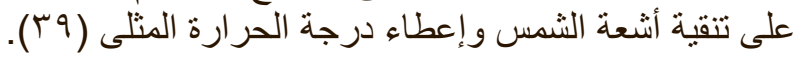

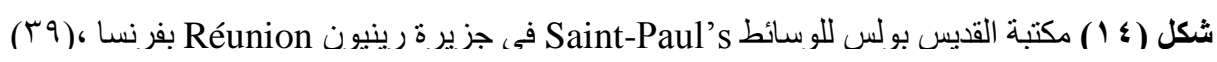

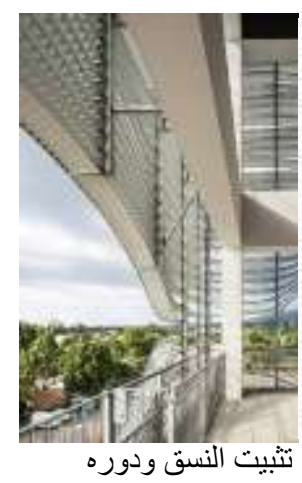

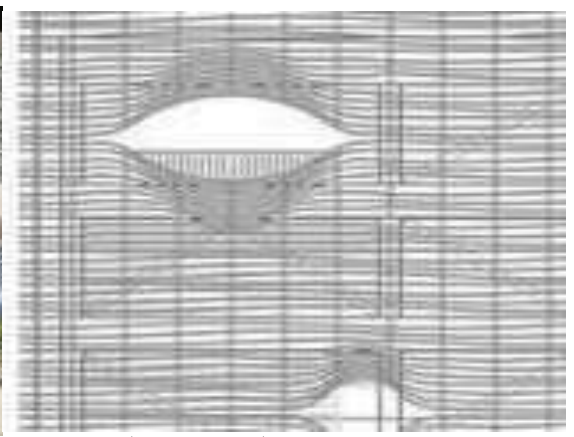

نسق بخط افقى ومتموج لتاكيد فكرة المشروع
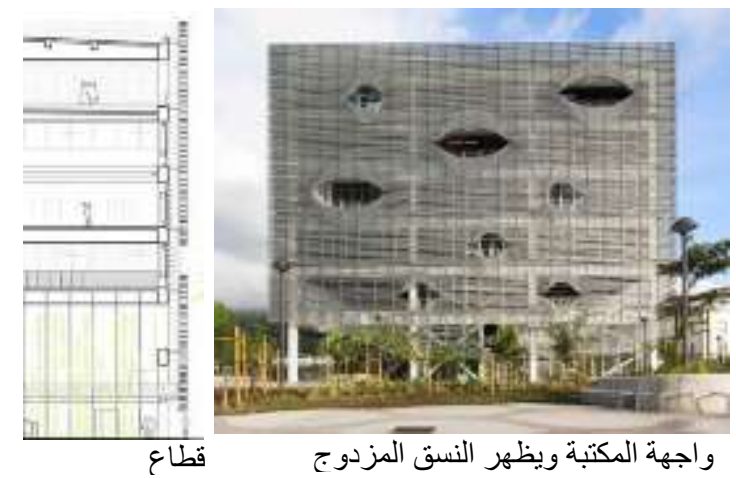

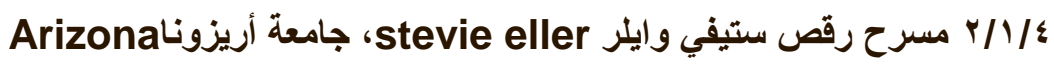

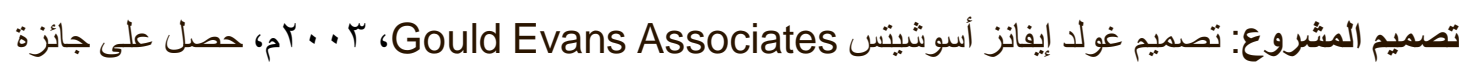

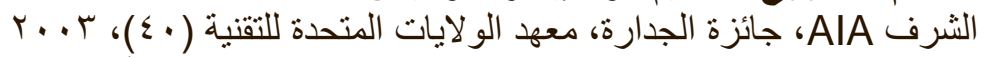

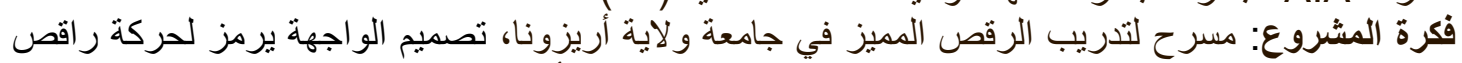

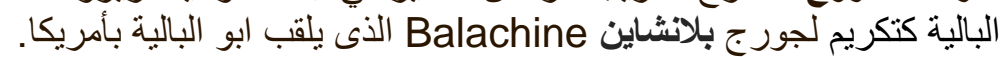

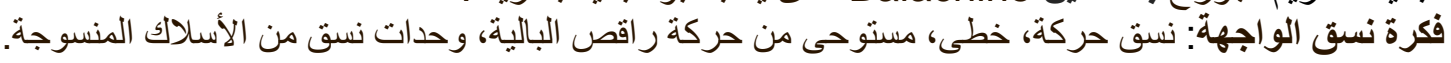

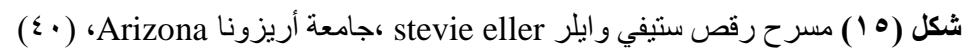

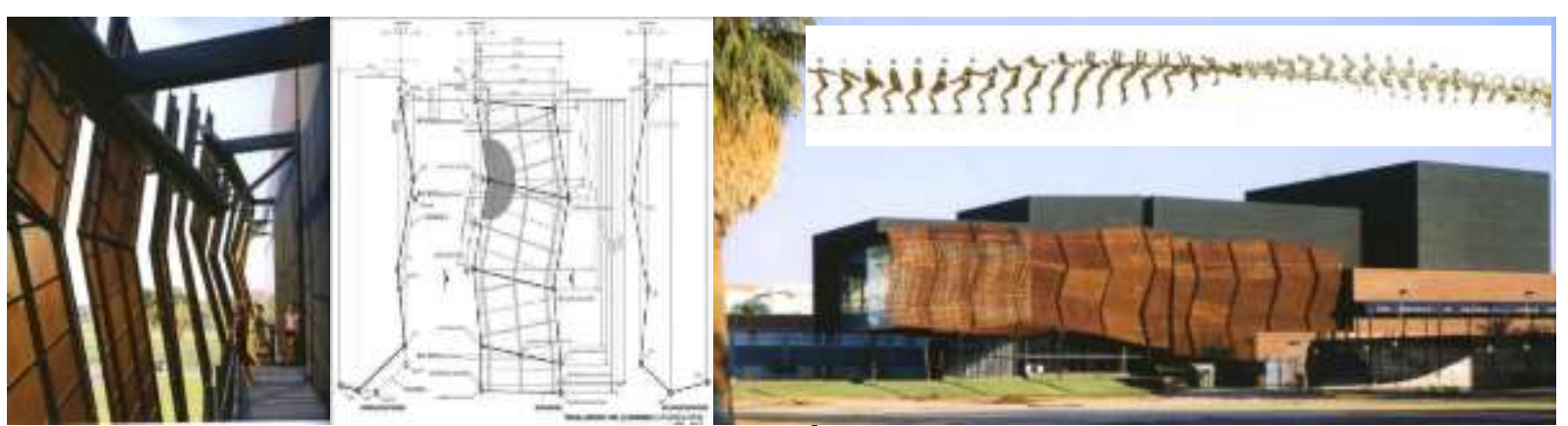

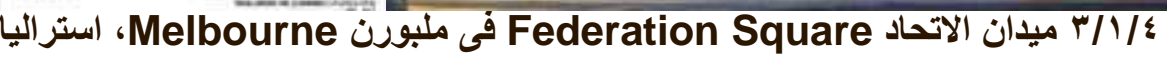

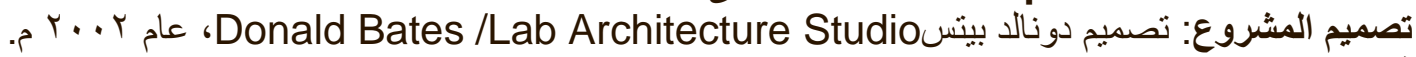

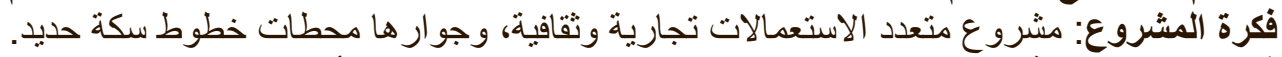

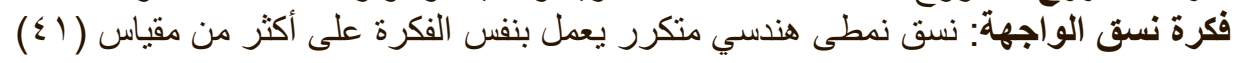


شكل ( 1 () ميدان الاتحاد Federation Square فى ملبورن Melbourne استر اليا ( (ع)
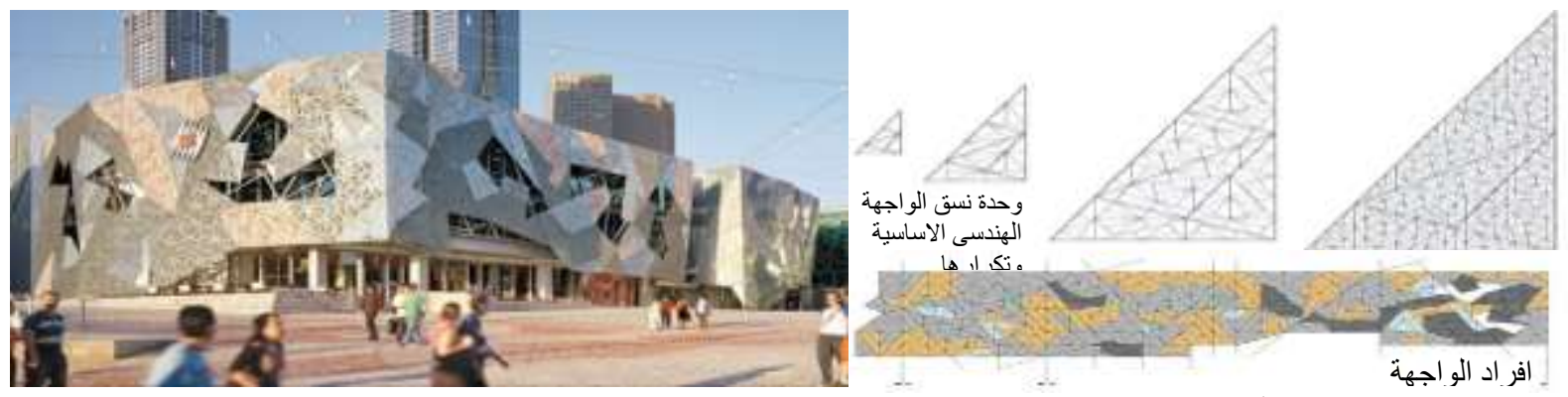

/ / / / اء نسق واجهة مستشفى المكسيك العام، hospital general Mexico

تصميم النسق: لشركة الزينة الانيقة Elegant Embellishments، النسق مُستخدم فى عدة مشرو عات

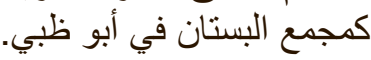

الجوائز: جائزة Julius Eslicher للعمارة الداخلية وجائزة الإضاءة المعمارية A.I.A MondoLuce

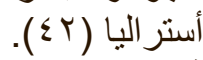

فكرة نسق الواجهة: أصل النسق وحدة زخرفية هندسية. هناك طبقة من ثاني أكسيد التيتانيوم TIO، عندما

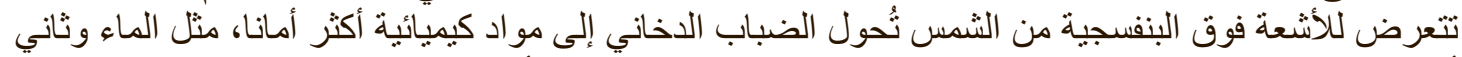

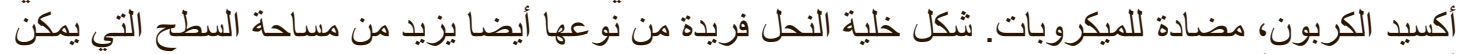

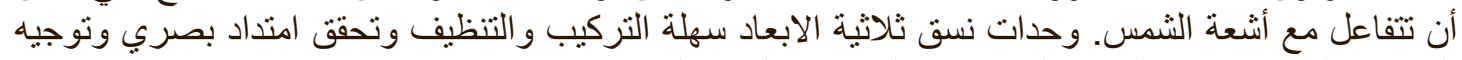

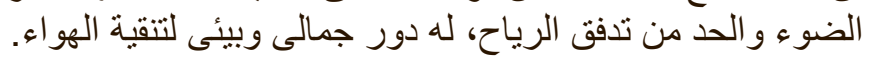

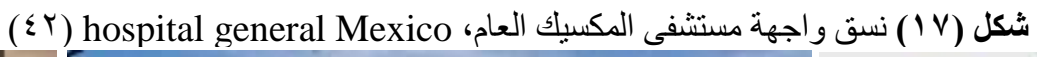
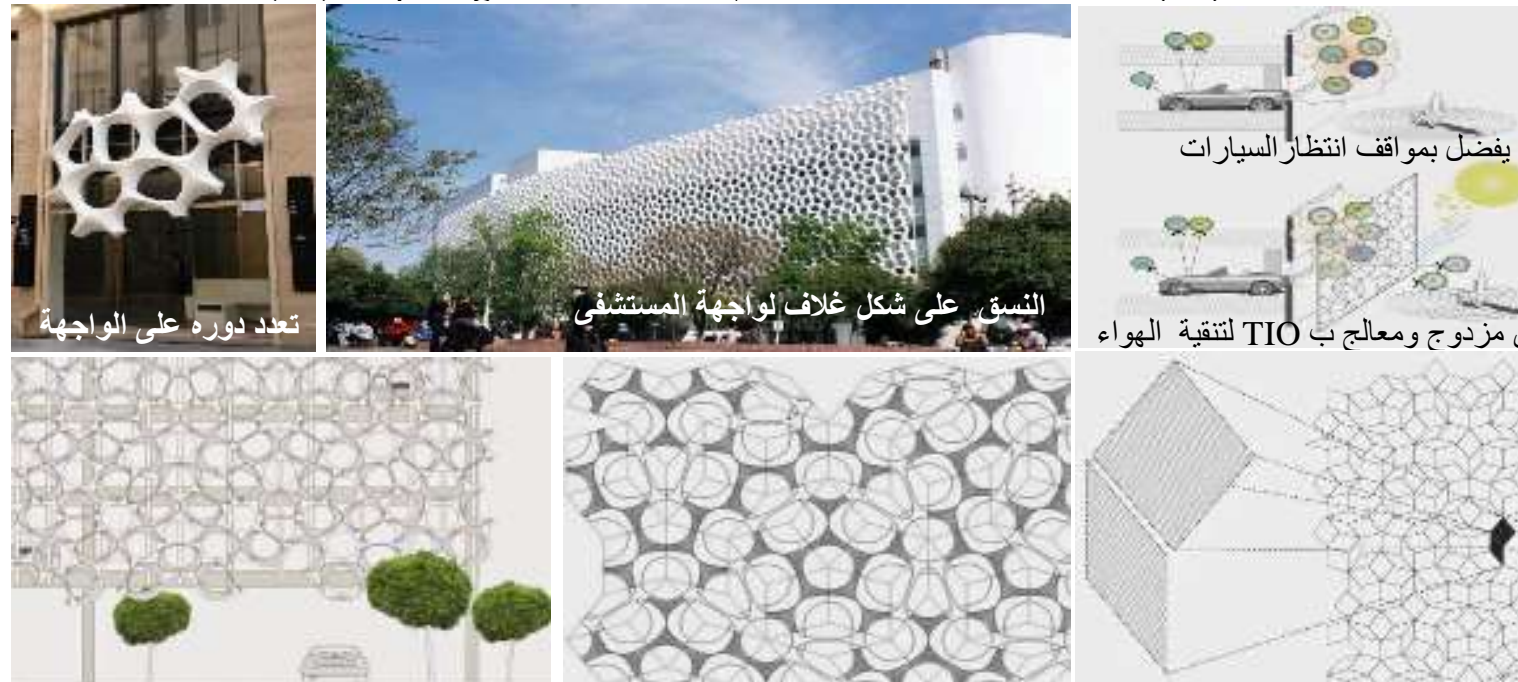

فكرة النسق على الواجهة

شكل خلية النحل يزيد من المسطح المعرض للنشس

اصل وحدة النسق هندسيا

MSK Memorial Sloan-Kettering Cancer / / / مركزميموريال سلون كيترينج للسرطان

(Center's)

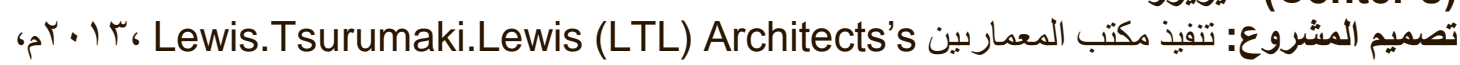

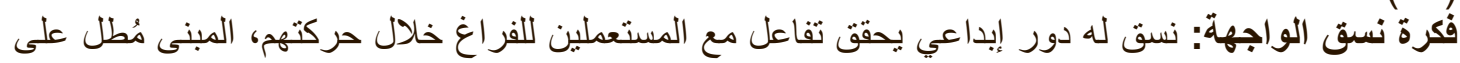

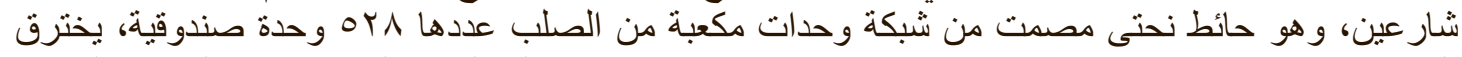

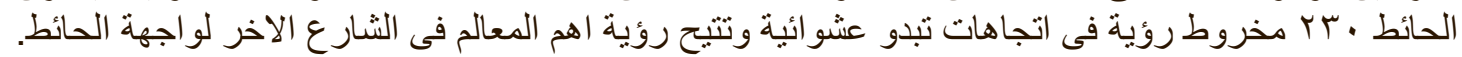

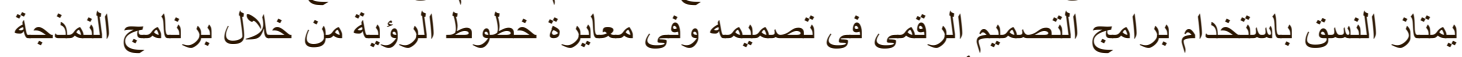

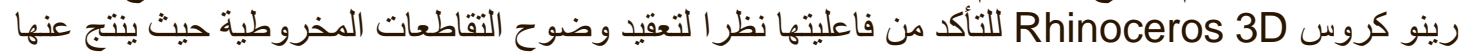

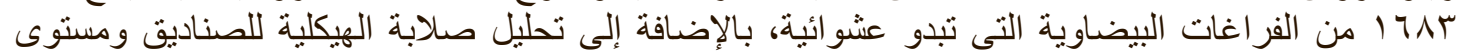

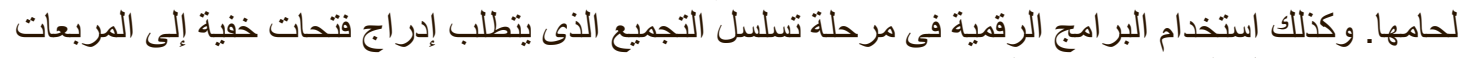
لا يمكن ان تصل اليها يد الإنسان لتجميعها الركية فيرا 
شكل (^ 1) نسق حائط مركز ميموريال سلون كيترينج للسرطان MSK Memorial Sloan-Kettering، نيويورك (بـ )
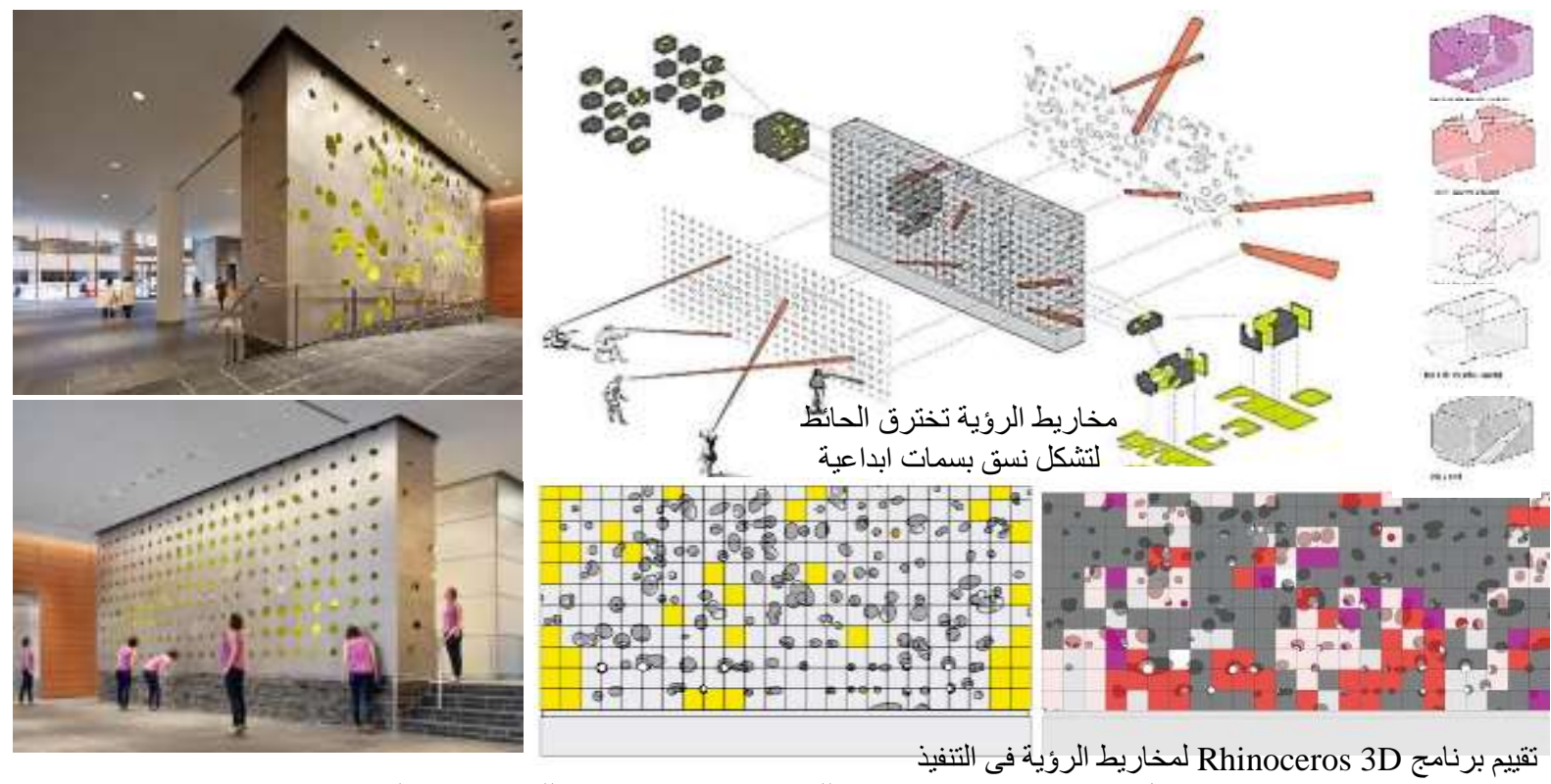

مكعب ابيض جيد ،مكعب رمادى مقبول ،مكعب اصفرزو ائائ ضعيفة اللحام ، مكعب احمر سيئ اللحام من احد الجو انب ، مكعب موف مرفوض

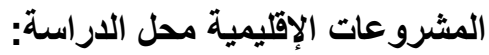

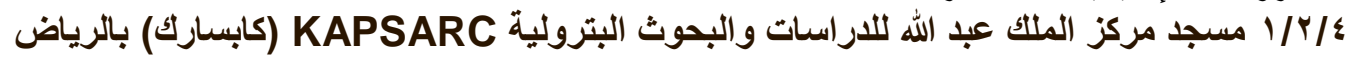

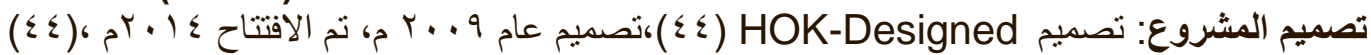

الجوائز: فائز بمسابقة دولية للتصميم المعماري.

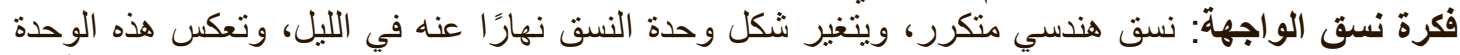

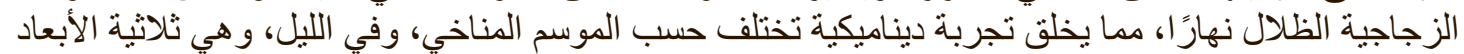

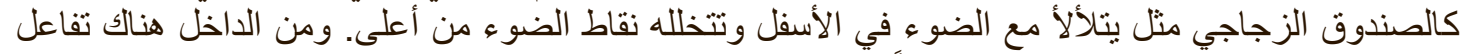

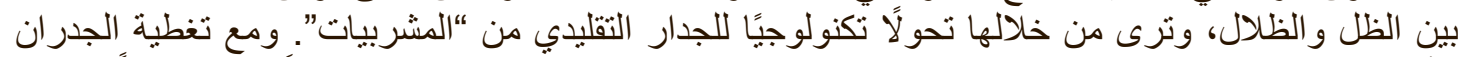

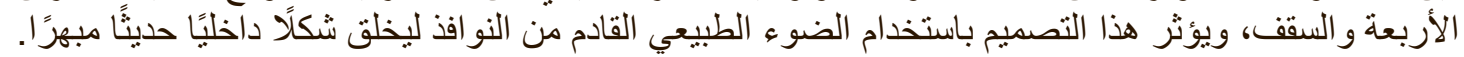

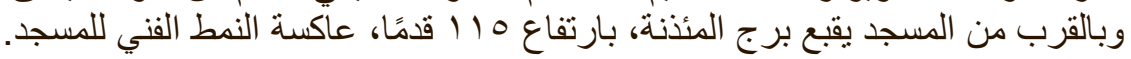

شكل (9 (1) نسق الغلاف، مسجد مركز الملك عبد الله للار اسات والبحوث البترولية، ( ع ؟)
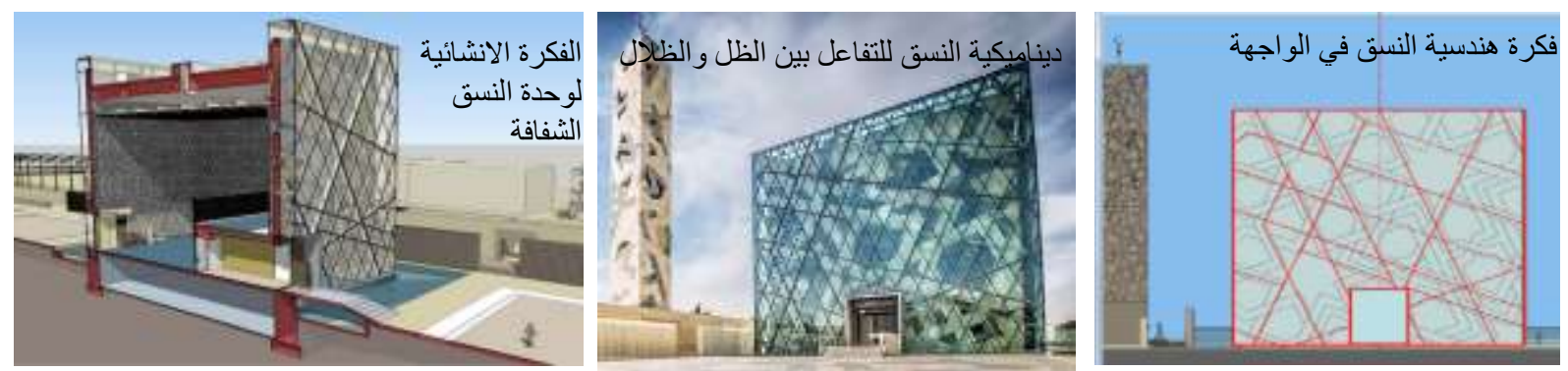

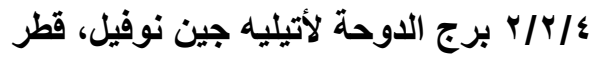

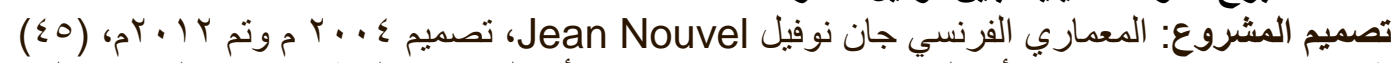

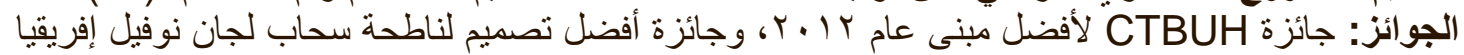

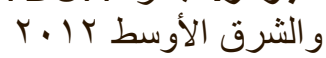
فكرة نسث الواجهة: هندسي منتظم ومتكرر، حيث بتم تغليف البرج بأكمله بطبقة للنظليل بواسطة شاثشات Screen بوحدة المشربية الزخرفية للتعبير عن طابع المنطقة العربى، يحتوي الغلاف على على حدائق علوية. 


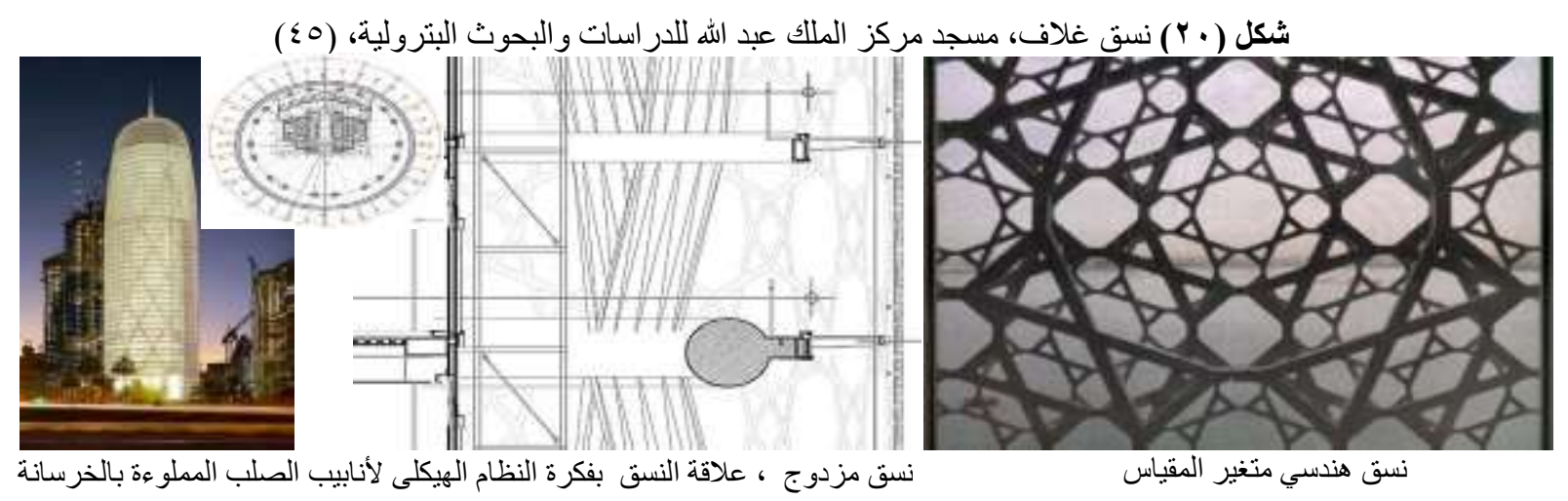

كإ/ أبراج البحرAl-Bahr مقر مجلس أبو ظبي للاستثمار ،أبو ظبي، الإمارات العربية المتحدة

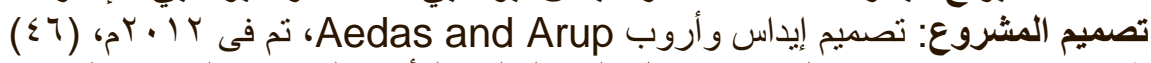

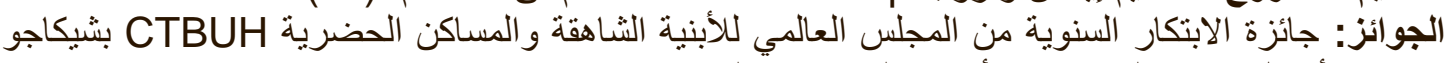

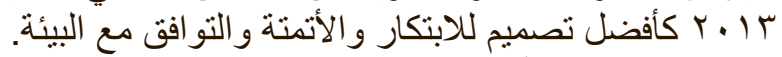

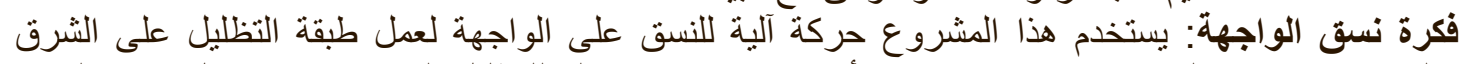

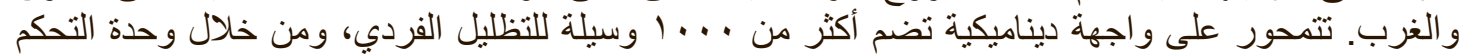
تفتح وتغلق وفقا لمسار الثمس. وتتكون كل وحدة من لوحات السليكون PTFE لتحقيق إمكانية التمدد و الانضغناط.

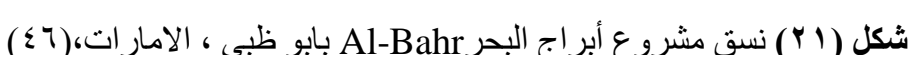
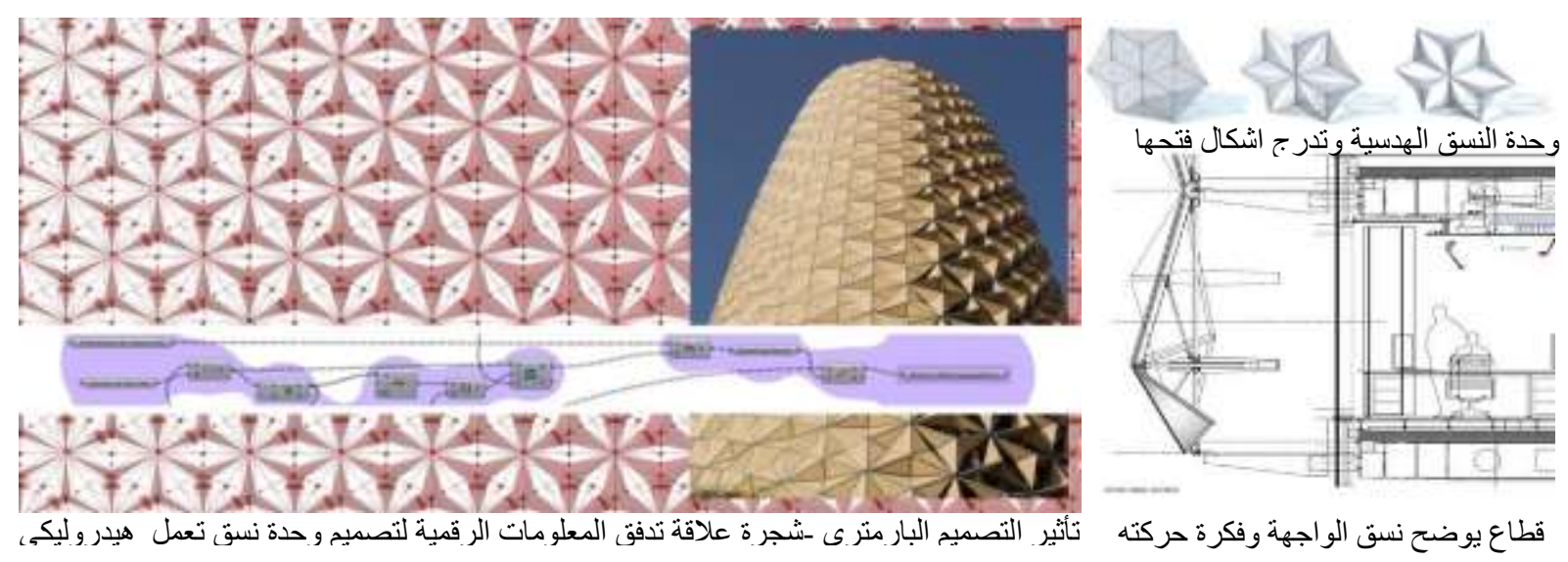

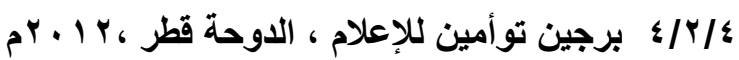

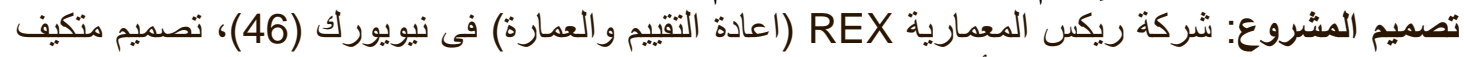

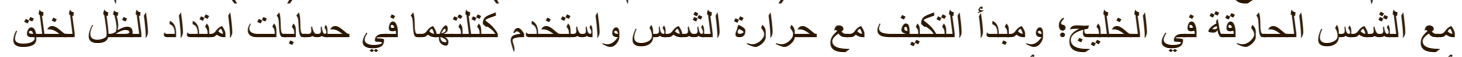

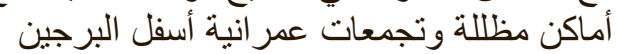

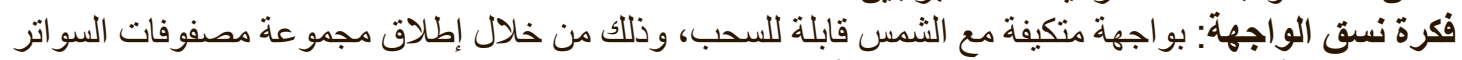

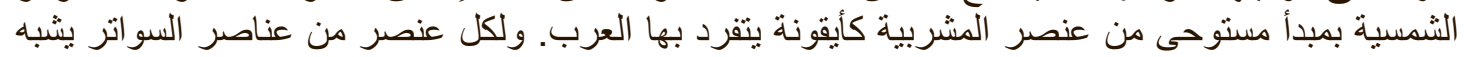

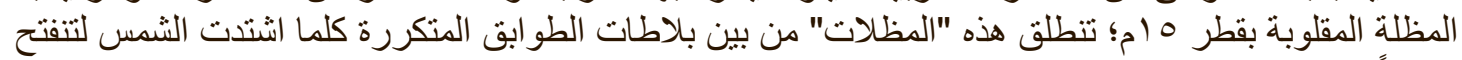

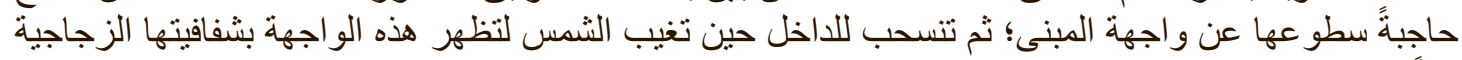
ليلاً وتعمل كثاشة تلفاز هائلة تعرض ما تعرضك نه هذه الثركات الإعلامية في البرجين. 


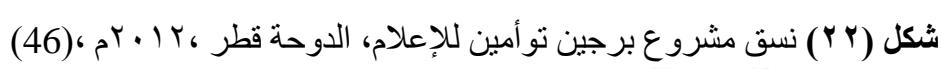
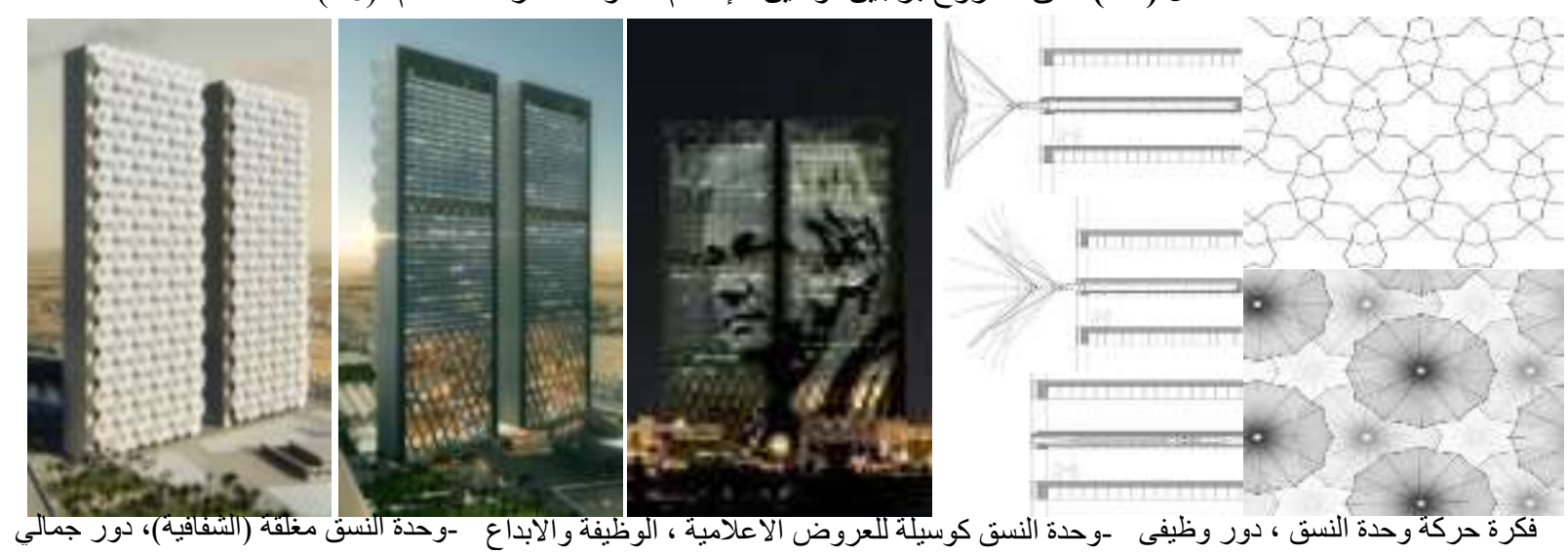

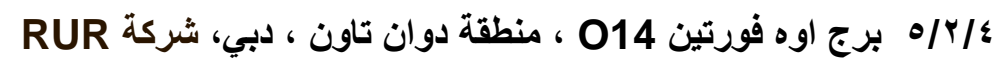

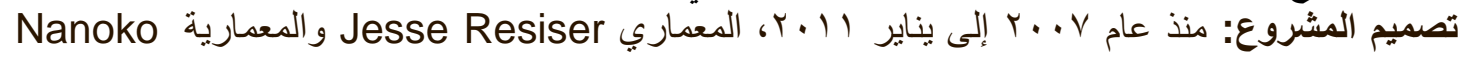
Umemoto

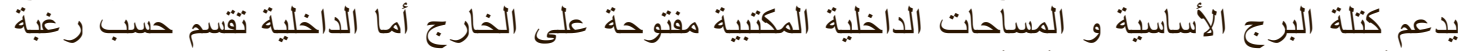

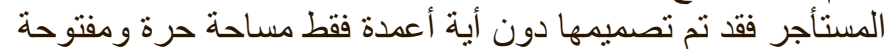
الجوائز: فاز التصميم بثلاث جوائز عالمية، أبرزها من المجلس الهندسى الأميركى و الجائزة الفضية من جوائز

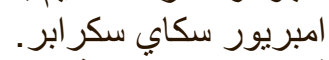

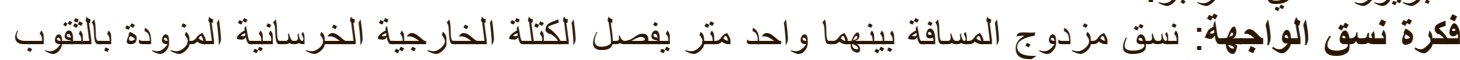

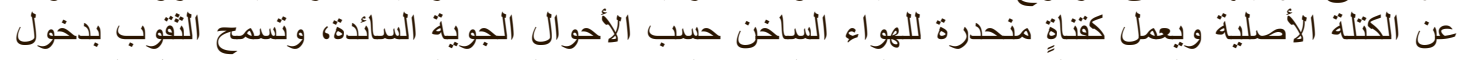

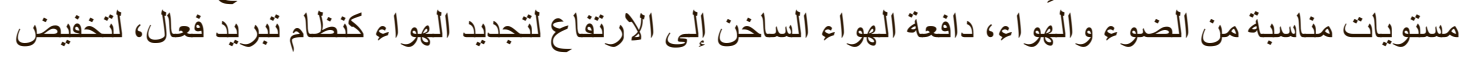

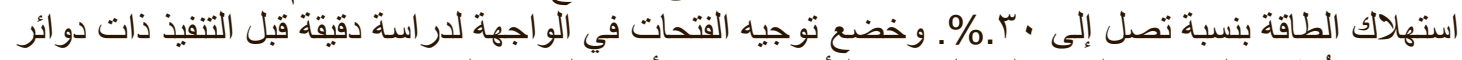

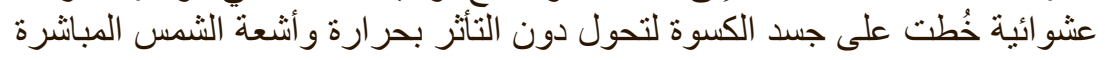

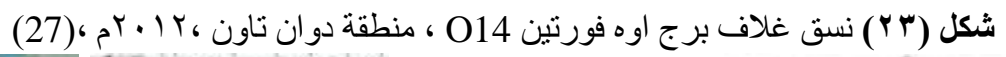
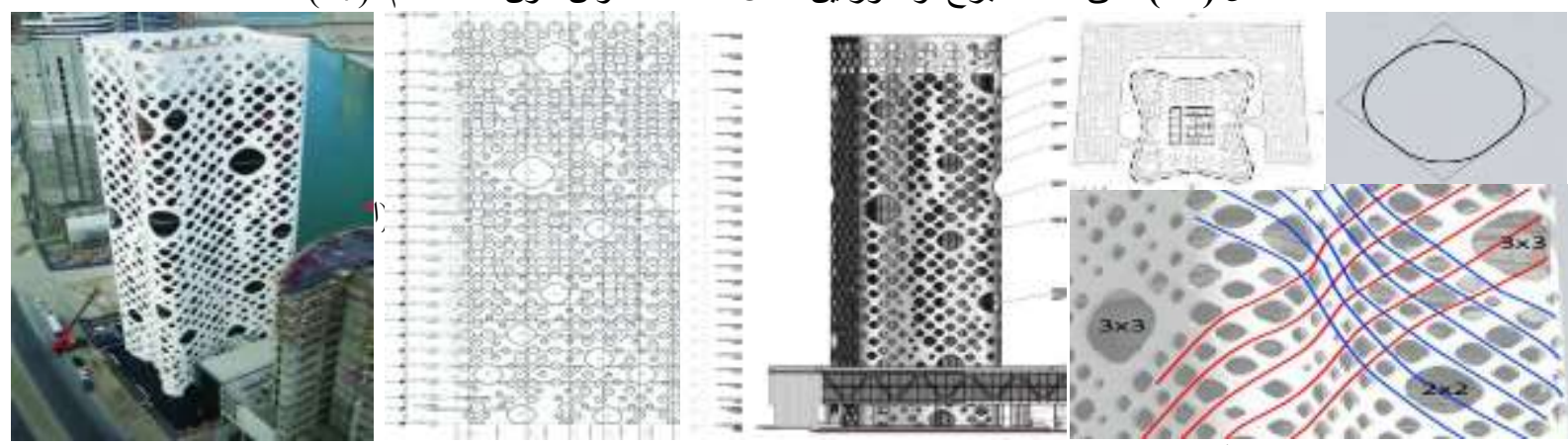

وحدة النسق متغيرة المقياس والأوضاع لتناسب التصميم البيئي- نسق مزدوج جمالي يسمح بتظيم مستويات الاضاءة والرؤية والتهوية ويدعم انثائيًا

\section{ب/ آ مقترحات المشروعات المحلية محل الاراسة:

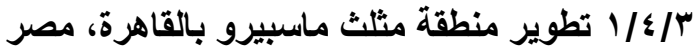

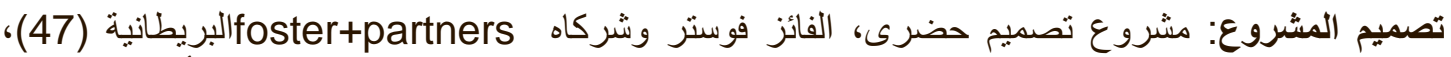

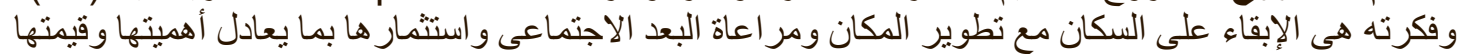

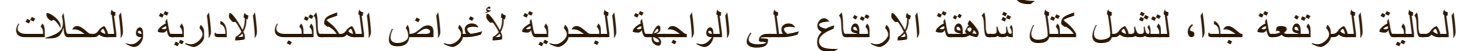

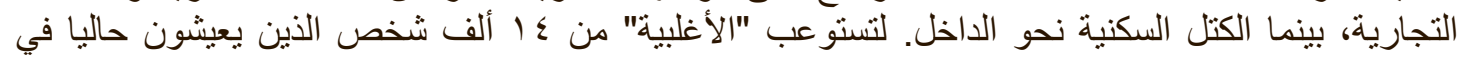

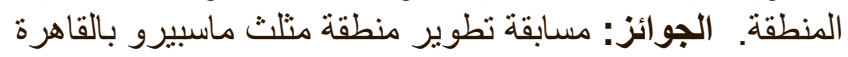


شكل ( ع Y) نسق و اجهات منطقة مثلث ماسبيرو بالقاهرة، (47)
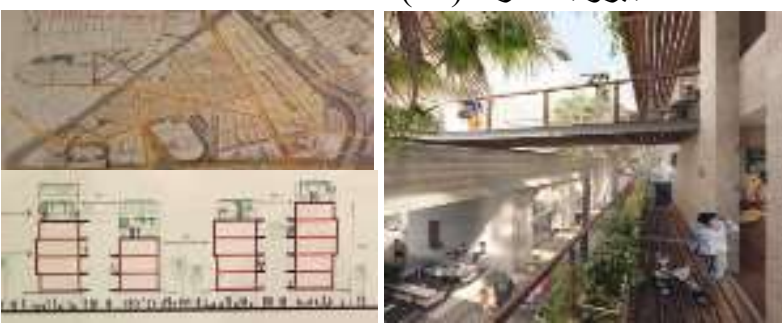

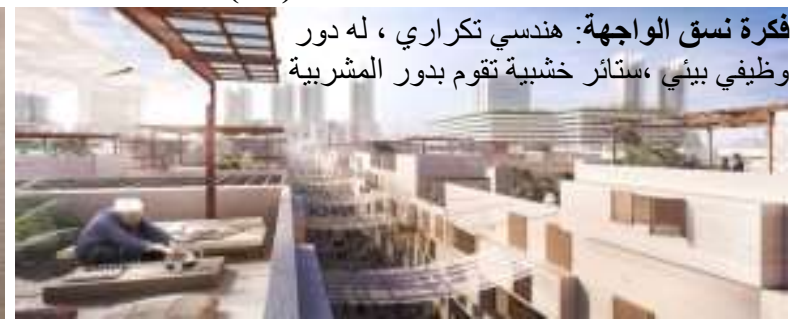

معالجات نسق بتوحيد الدهانات و الارتفاعات المنخفضة للمناطق السكنية ((المقياس)

Stone Towers عاب/ مشروع ستون تاورز بالقاهرة

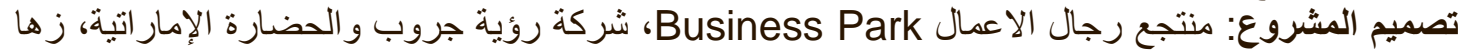

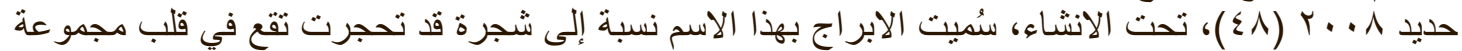

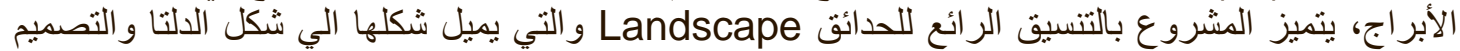

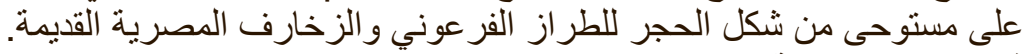

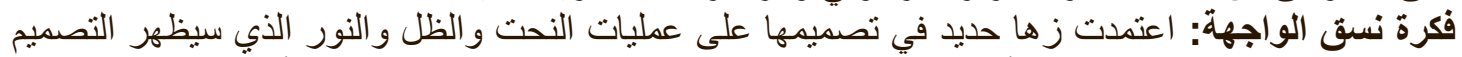

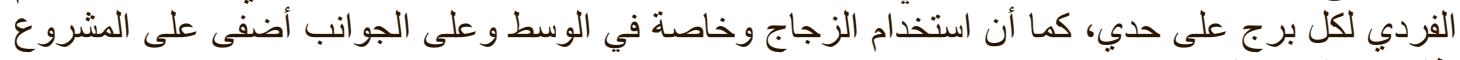

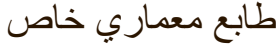

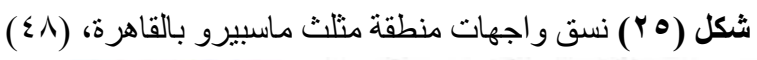
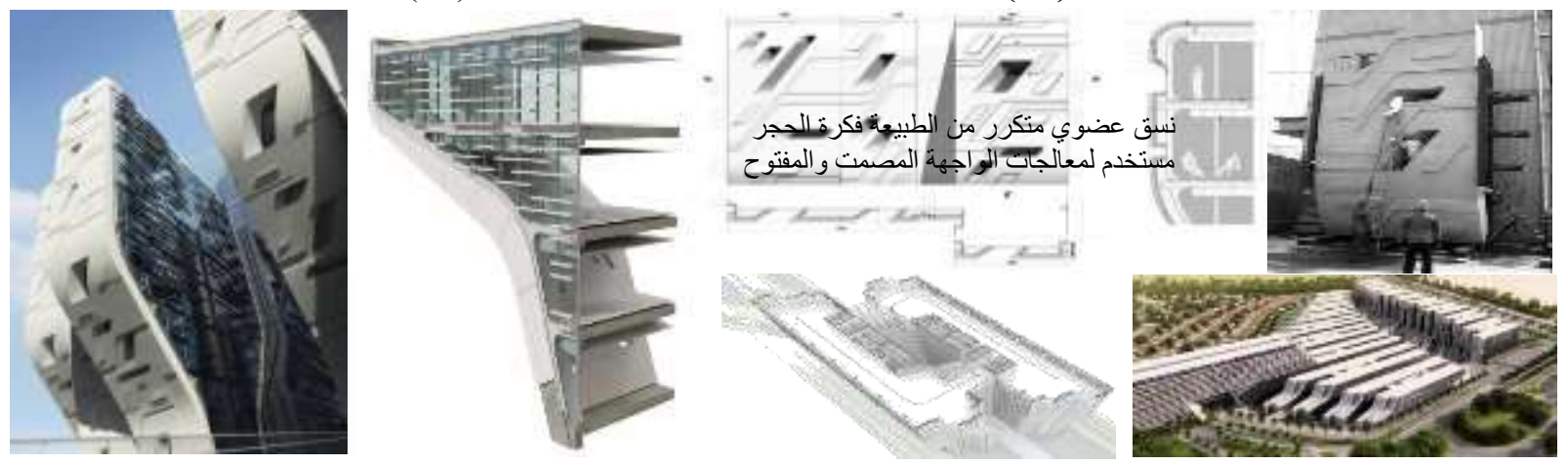

ك/T/The Gate Heliopolis بمصر مشروع الجديدة، القاهرة.

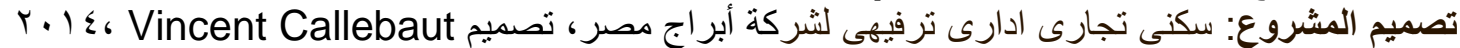

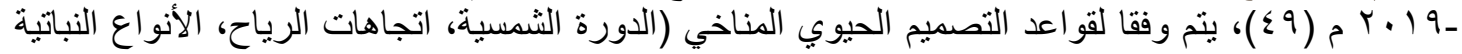

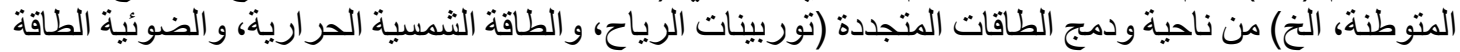

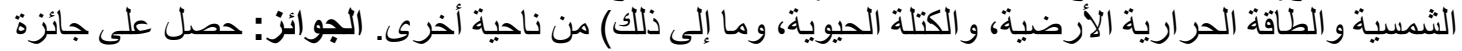

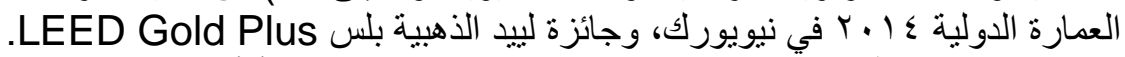

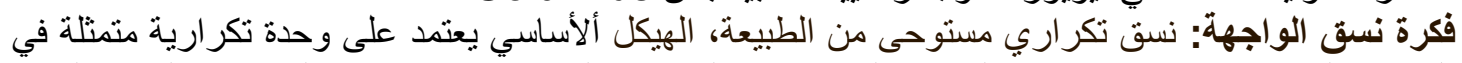

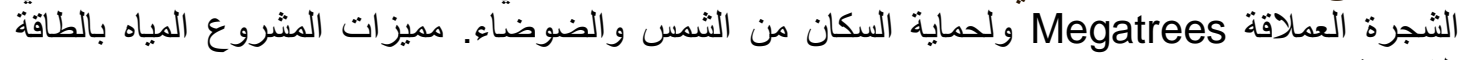

الثمسية.

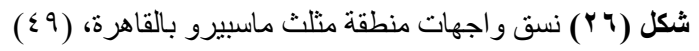
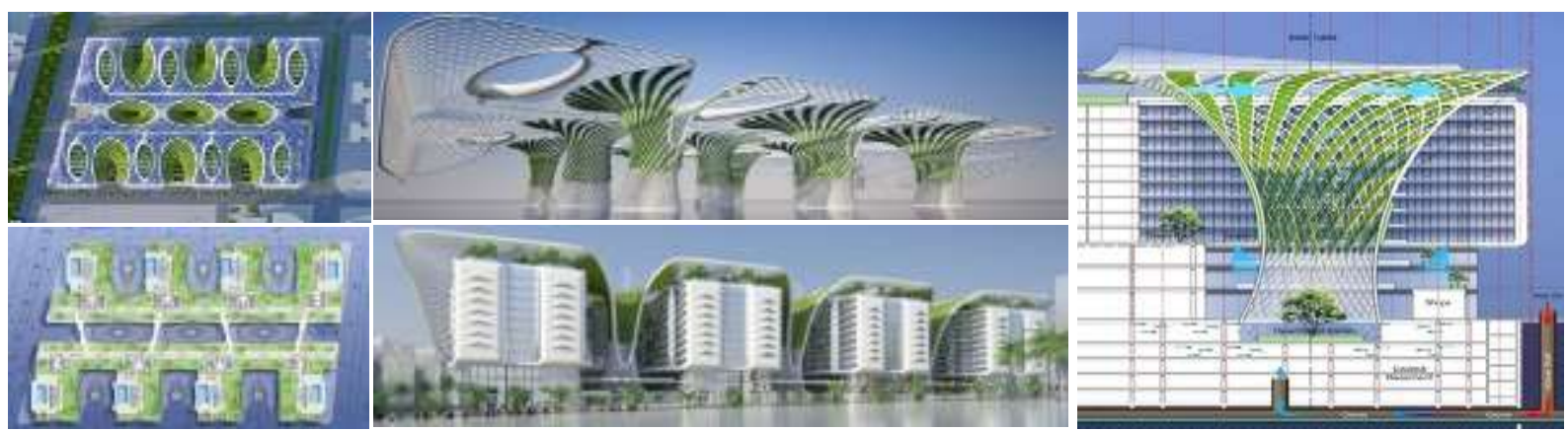

معالجات نسق انثائي وبيئي لتحقيق التهوية بتطوير فكرة الملقف في صورة شجرة مفرغة-نسق يعمل كمظلة للحماية الثمس ودمج توربينات الرياح و الخلايا الضوئية الثمسية 


\section{ك///؟ مفترح معالجة مبنى مكتبة الاسكندرية ليتوافت مع البيئة}

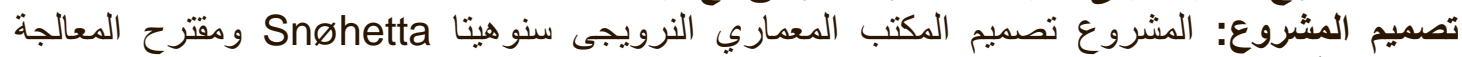
للمعمارى أسامة عمر (0. (0.

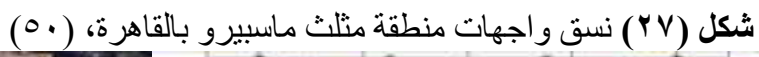

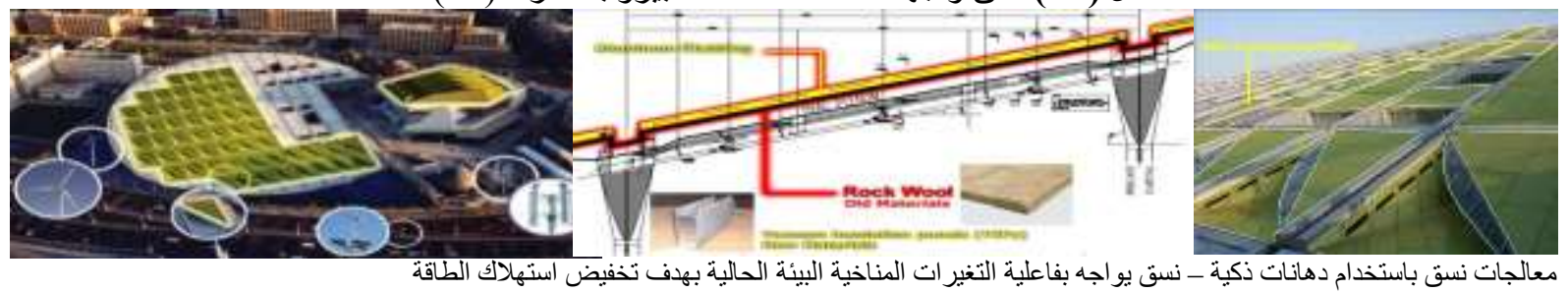

فكرة نسق الواجهة: نسق صديق للبيئة، باستبدال الزجاج القديم بدهانات نانوية لحماية سقف المكتبة ودمج

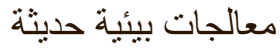

ع/آ/ه المتحف المصرى الكبير: ميدان الرماية، الجيزة، المعمارى Heneghan peng (شركة أيرلندية)

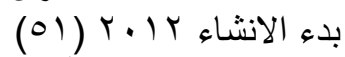
فكرة نسق الواجهة: تم تشكيل واجهتي المتحف بتكرار متتابع لوحده هندسيه مثلثة الثكل تسمى "منلث

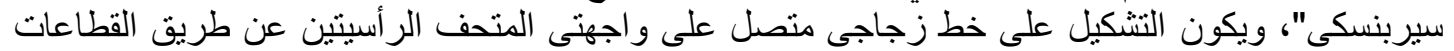

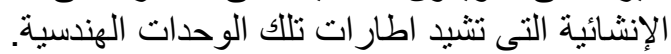

شكل (Y) نسق و اجهات منطقة مثلث ماسبيرو بالقاهرة، (0)

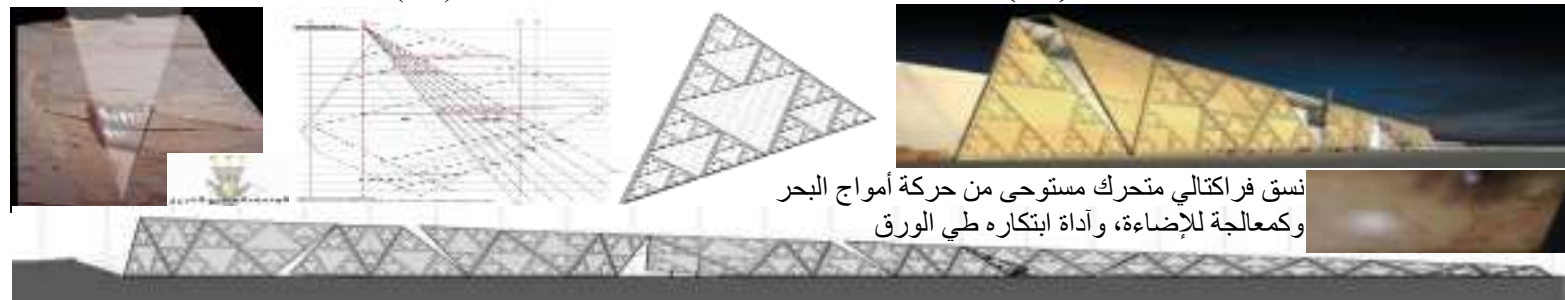


جدول ( ) يوضح دراسة تحليلية مقارنة لسمات النسق و ادوات ابتكاره وتطور دور النسق ومستويات معالجة الو اجهات لمشرو عات محل الدراسة

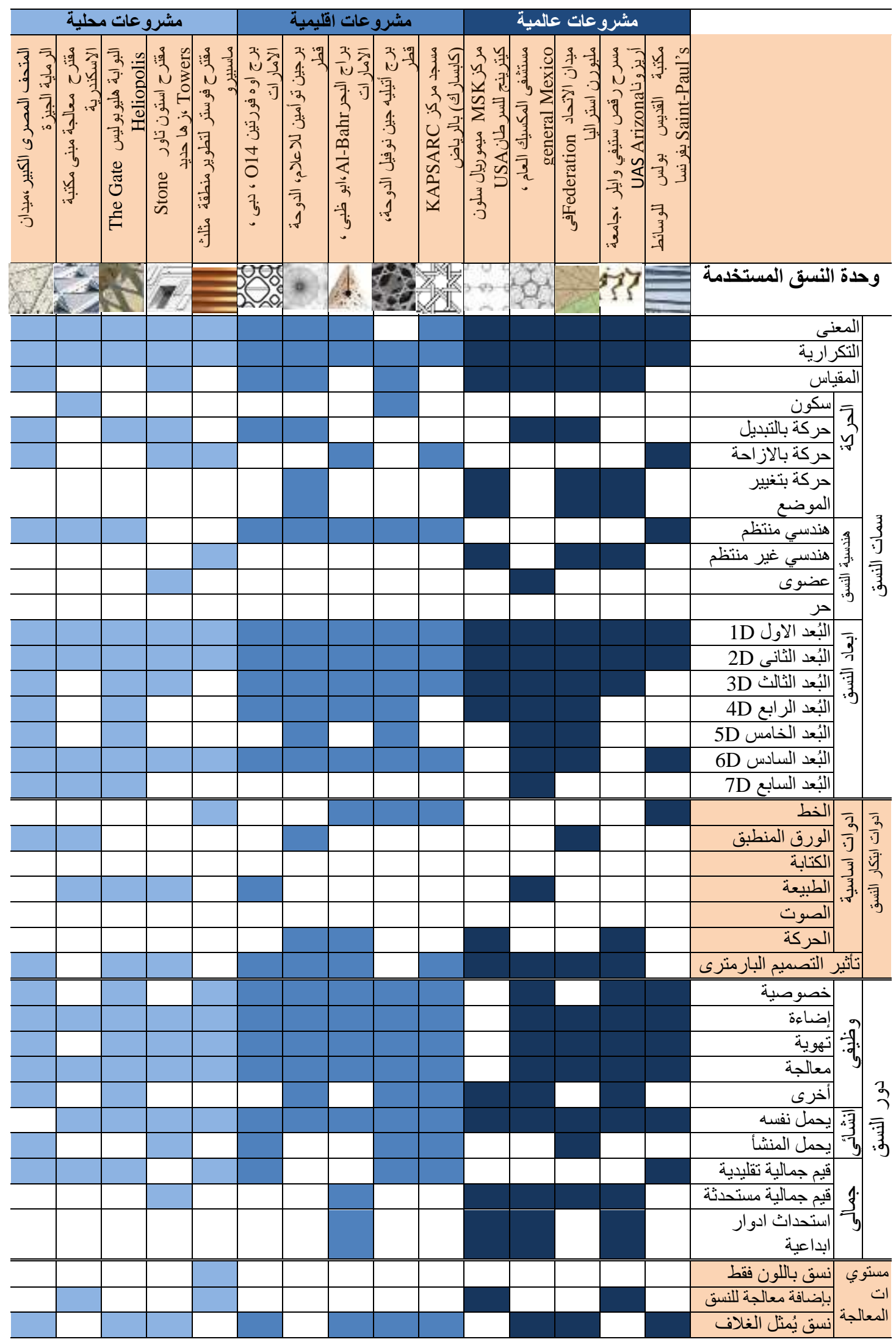




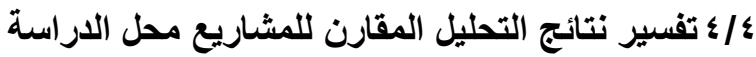

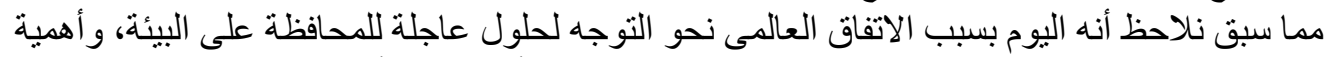

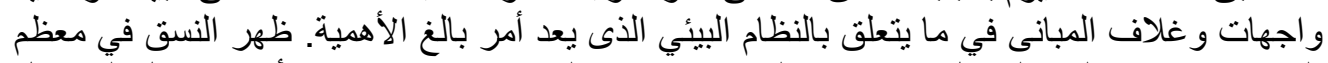

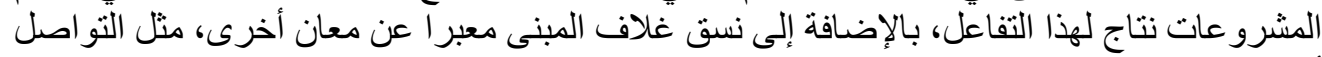

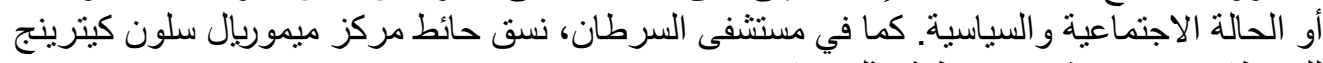

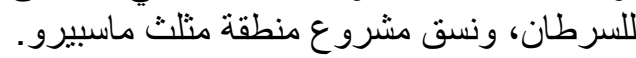

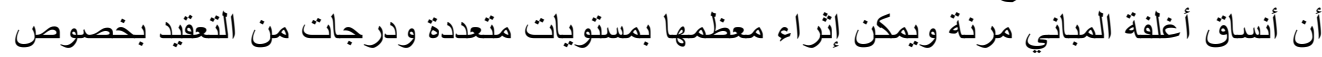

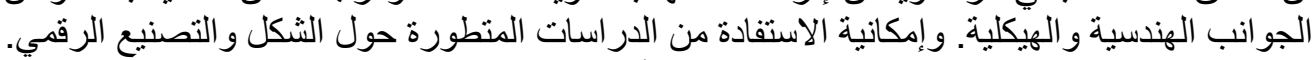

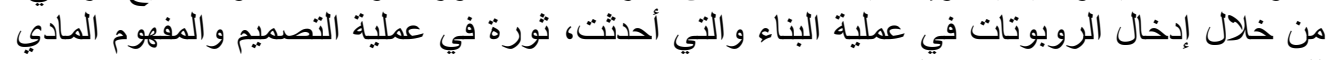
للنسق، و إمكانية إعادة الإنتاج التّنتي.

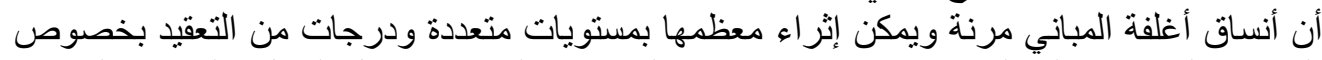

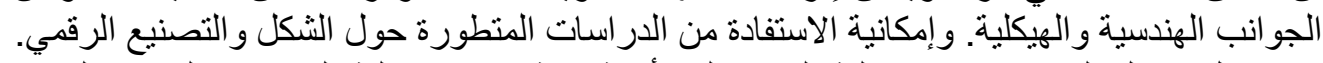

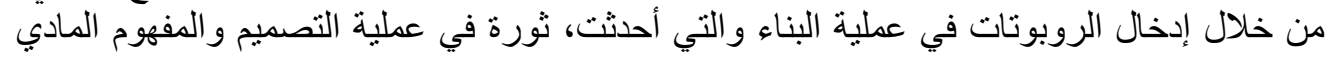
لللنشق، و إمكانية إعادة الإنتاج آلتنقني.

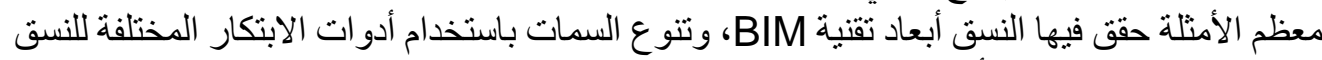

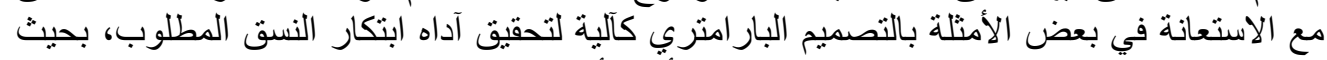

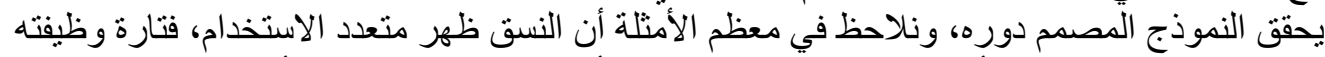

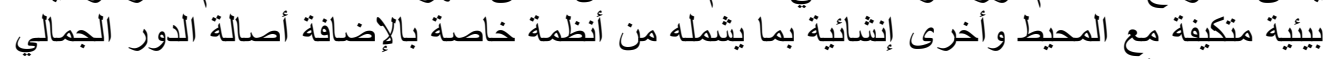
لمعظم هذه الأنساق. ويمكن إجمال تفسير النتائج التي توصلت إليها الديأ الدراسة والتي يمكن من خلالها استخلاص الداروس

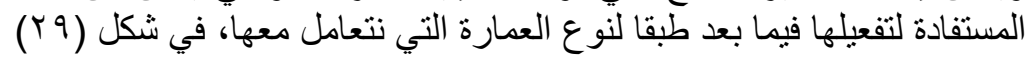

شكل (q ץ) تأثير دور النسق المعماري كأداة لتشكيل وتصميم و اجهات المباني ومجالاته المتعددة، المصدر : الباحث

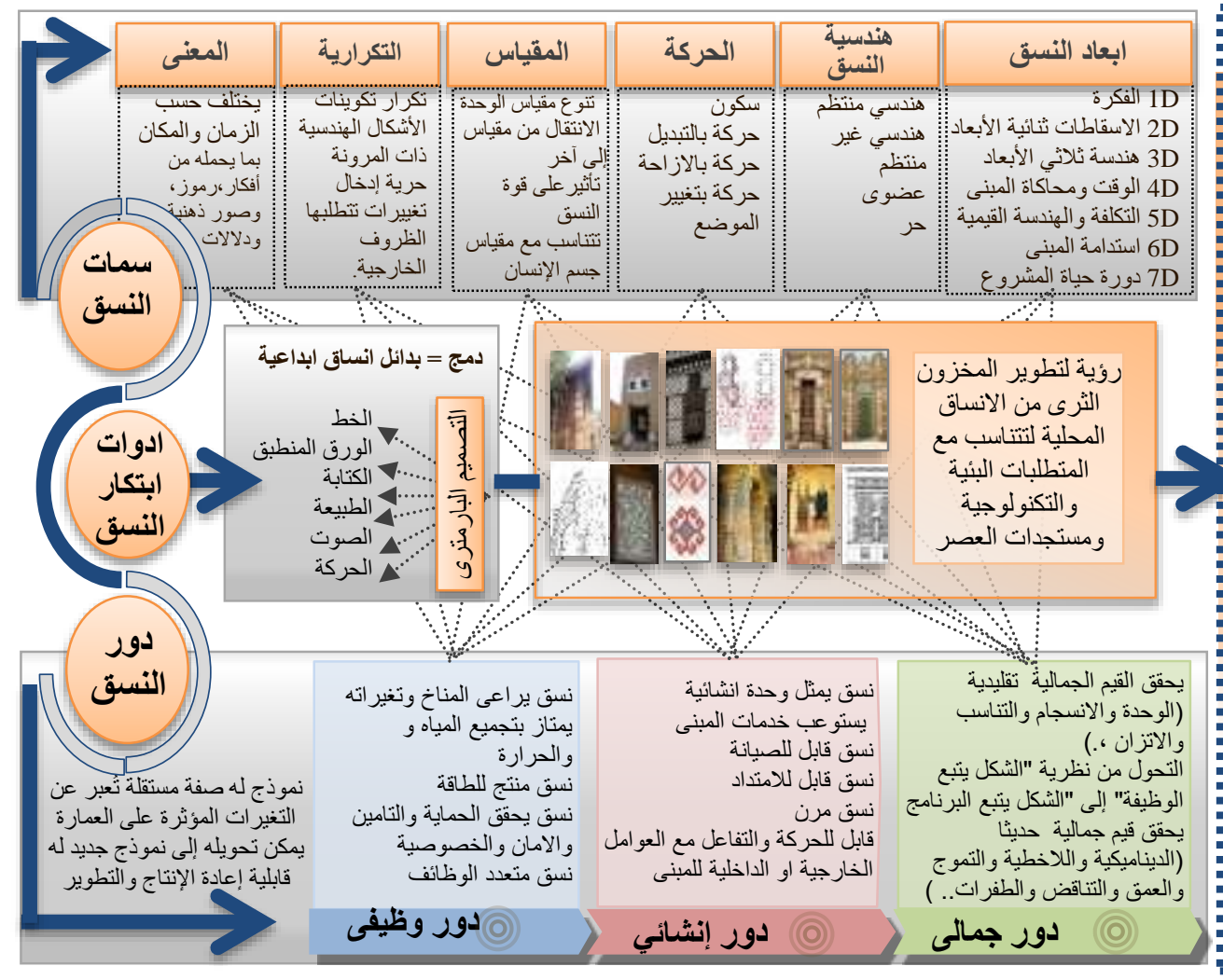

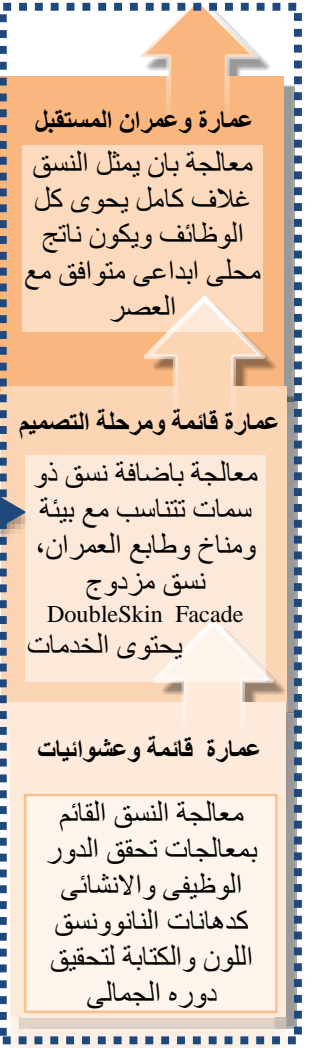




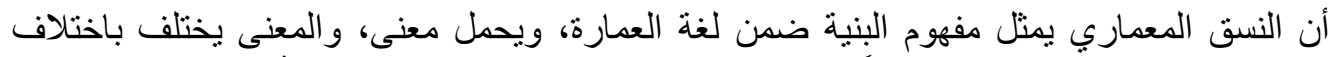

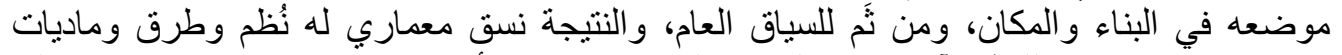

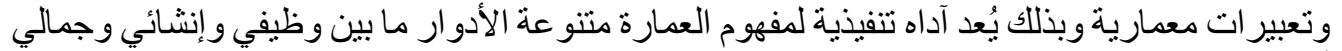

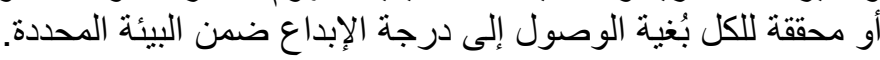

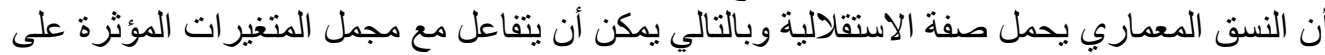

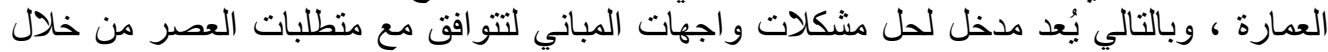

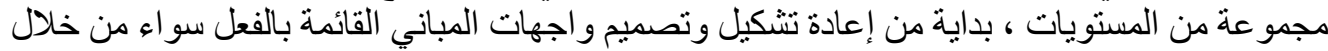

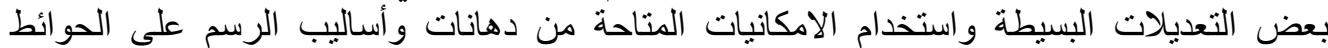

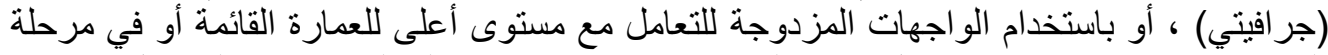

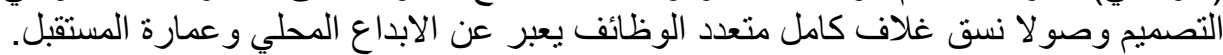

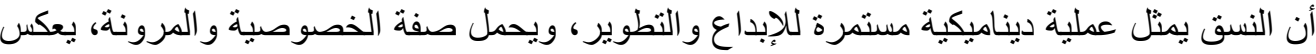

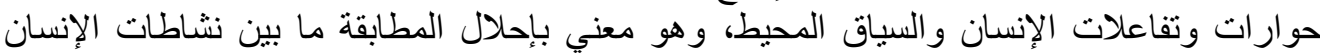

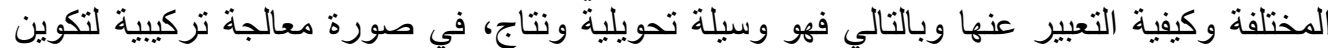
العلاقات المتبادلة والتي تربط بين البعد النظري و العملي لتوليد مظهر التهر البنية المادية. النسق هو كيفية الوصول الى وحدة يمكن تكر ارها بطرق متباينة وتكون متعددة الوظائف يمكن ان تساهم

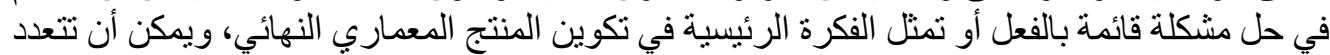

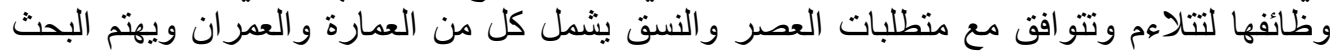
بدر استة نسق و اجهات المباني

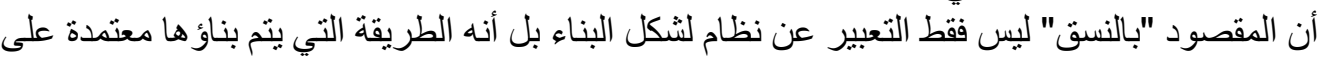
عملية التفاعل بين مستويات مختلفة: النشاط البشري، والأدوات وات والمواد و الثكل و البنية والبيئة و الاتصالات. r/o

يو صي البحث بالتركيز على تطوير الأنساق المعمارية المحلية باعتبار ها المكون الرئيسي لغلاف المباني

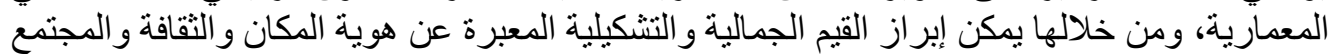
بما بتناسب مع منطلبات العصر ، وبالتالي الارتقاء بمستوى العير العمارة.

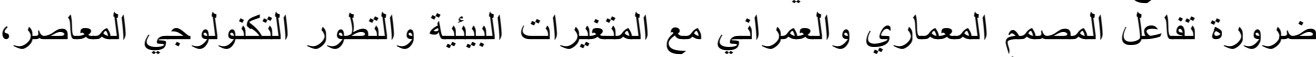

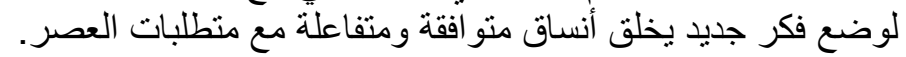

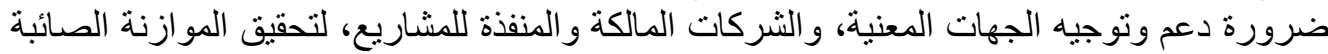
بين المؤثرات الو افدة والموروثة مع الاستفادة من كل إفراز ات التهات التقيات و التطورات المعاصرة، لتطوير الأنساق القائمة بالفعل، ودمج الحديث مع تاريخنا الحضاري وذئ وذللك لإيجاد أنساق معمارية مستمدة من

العمارة المصرية.

\section{مراجع البحث: - مرا:}

\section{References}

(1) http://gopp.gov.eg/eg-map /, acssesed at 3/1/2016

د.م. عبدالرحمن عبد النعيم، "إستلهام التراث العمرانى - من الإستنساخ إلى تأصيل و إستدامة العمارة والعمران

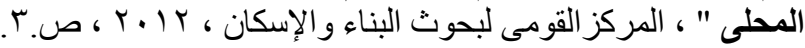

(3) http://www.egyptedantan.com/egypt.htm, acssesed at 5 / 1/2016

(4) Dr. Mohamed M Nour El-Din,"Climate Change Risk Management in Egypt Proposed Climate Change Adaptation Strategy", Ministry of Water Resources \& Irrigation in Egypt “, Joint Programme for Climate Change Risk Management in Egypt, January 2013, Prepared for UNESCO-Cairo Office, p.4

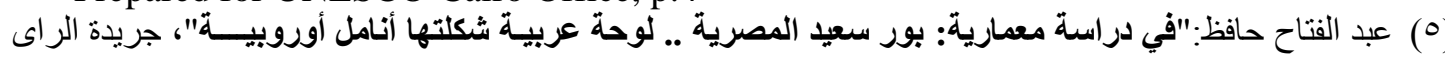

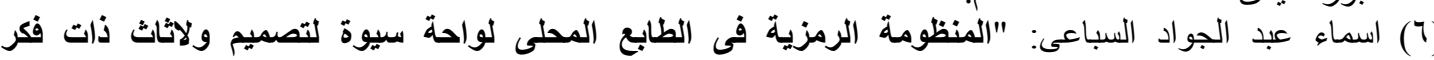

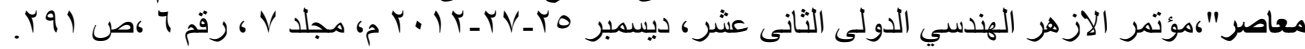

(7) http://www.almaany.com/ar/dict/ar-ar/, acssesed at 10/2/2016. 


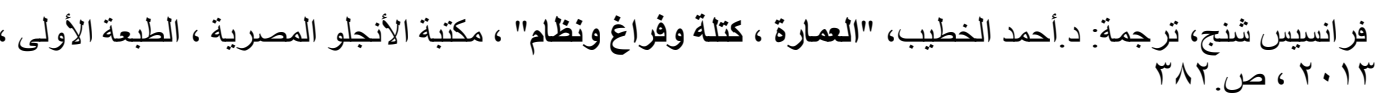

(9) Christopher Alexander - Ishikawa, Sara - Silverstein, Murray, "A Pattern Language:

Towns, Buildings, Construction”, Published Book, New York: Oxford UP, 1977.

(10) Christopher Alexander, "The Nature of Order" (Oxford University Press, New York), 2001.

(11) Nikos A. Salingaros and Terry M. Mikiten, "Darwinian Processes and Memes in Architecture: A Memetic Theory of Modernism", Journal of Memetics <jomemit.cfpm.org/2002/vol6>. Reprinted in DATUTOP Journal of Architectural Theory, 2002, P. 117-139.

(12) C. Zappulla, "Per una Scienza Architettonica del Pattern? " PhD thesis, Barcelona: Universitat Politècnica de Catalunya, Departament de Projectes Arquitectònics, 2014,P.75.

(13) Carmelo Zappulla,"Techno-pattern: Skin, Environment and Fabrication", IAAC/UPC-GIRAS, Palimpsesto, Polytechnic University of Catalonia, Barcelona, October 2014, No.11, p. 10-11.

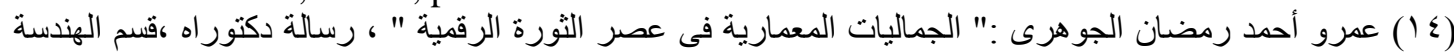

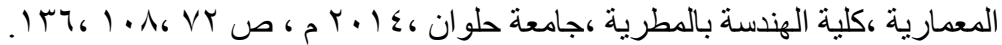

(15) http://artsgulf.com/610013.html, Acssesed at 20/ 4/2016

(16) http://www.kriskadecor.com/en/casestudies/kriskadecor-clads-the-full-fa\%C3\%A7adeof-the-ecuador-pavilion-at-the-expo-milan-2015-14

(17) https://www.pinterest.com/wanderinggamine/b-u-i-l-d-i-n-g, acssesed at 23/4/2016

(18) http://www.hierve.com/projects/hesiodo/fotografia/, acssesed at 16/6/2016

(19) ___ "Environmental ReportExpo 2010 Shanghai China", Bureau of Shanghai World Expo Coordination, Shanghai Environmental Protection Bureau ,2009, P.83.

(20) https://danielraznick.com/about/adaptive-solar-skin/, acssesed at 8/ 7/2016

(21) http://tdcoffice.com/architecture/saba-apartment, acssesed at 9/7/2016

(22) http://www.abeerseikaly.com/weavinghome.php, acssesed at 18/6/2016

(23) Andrea Simitch \& Val Warke," the language of architecture - 26 Principles Every Architect Should Know ", Rockport Publishers, Quarto Publishing Group USA Inc, 2014, P.p 33

(24) http://www.freelandbuck.com/projects/maximiliano/ acssesed at 29/10/2016.

(25) Helmut Pottmann:" Geometry and New and Future Spatial Patterns", Patterns of Architecture-Architectural Design, November/December 2009, Vol 79, No: 6, John Wiley \& Sons, London, UK, P.62.

(26) http://www.egypty.com/egyptana/arts_culture/rashid_museum.asp, acssesed at 7/9 /2016

(27) Nick Dunn:" Digital Fabrication in Architecture", Laurence King Publishing Limited, London, 2012, P.65, 50.

(28) Y. Elghazi, A. Wagdy, S. Mohamed \& A. Hassan: "Daylighting Driven Design: Optimizg Kaleidocyle Façade for Hot Arid Climate ", Fifth German-Austrian IBPSA Conference, RWTH Aachen University, BauSIM 2014, Pp315.

(29) http://www.de-simone.com/projects/project/al-ain-grand-mosque acssesed at 11/9 /2016

(30) Ilaria Mazzoleni:"Architecture Follows Nature-Biomimetic Principles for Innovative Design",CRC Press,Taylor \& Francis Group,2013 ,Pp 26.

(31) http://tripegypt.ru/content/kurorty-egipta, acssesed at 2/11/2016.

(32) Adrian Smith\&Gordon Gill:"Dancing Dragons Seoul,

Korea",http://smithgill.com/media/pdfs/dancing_dragons_for_web1.pdf

(33) http://brothersdressler.com/lululemon, acssesed at 20/5/2016

(34) http://www.archdaily.com/285131/danial-reza-sayadian-sara-kalantary, acssesed at 9/10 12016

(35) http://www.calatrava.com/projects/reggio-emilia-stazione-mediopadana-reggioemilia.html 
(36) Philip Jodidio:"Calatrava, Complete Works 1979- Today", Taschen Publisher; Mul edition (November 25, 2015), P.34.

(37) http://www.dzarchitect.com/, acssesed at 5/10/2016

(38) Antoine Picon: "Ornament, the Politics of Architecture and Subjectivity", Architectural Design Primer, Mar 2013, John Wiley \& Sons, Artmedia, London, UK, Pp.136.

(39) http://www.peripheriques-architectes.com/m\%C3\%A9diath\%C3\%A8que-saint-paul

(40) Philip Jodidio:" stevie eller dance theatre “, Architecture Now, Vol. 3, English Edition, Taschen Publisher, November 17, 2004, Pp. 198

(41) Branko Kolarevic\& Kevin Klinge," Manufacturing Material Effects: Rethinking Design and Making in Architecture ", First Edition, Routledge published, New York, 2008, P.p 165,166

(42) http://www.smart-magazine.com/en/smog-eating-facades/, acssesed at 5/10 /2016.

(43) Paul Lewis, Marc Tsurumaki, David J. Lewis, "Lewis.Tsurumaki. Lewis Intensities"Princeton Architectural Press, New York, 2013, Pp.86

(44) http://www.hok.com/about/news/2014/12/23/

(45) George Katodrytis \& Kevin Mitchell:"UAE and the Gulf Architecture and Urbanism Now", Architectural Design, January/February 2015, No: 233, John Wiley \& Sons, Artmedia, London, UK, P.64.

(46) Branko Kolarevic\&Vera Parlac:" Building Dynamics: Exploring Architecture of Change", Routledge, New York, 2015, Pp.117, 124.

(47) http://www.fosterandpartners.com/news/archive/2015/11/foster-partners-wins-masperotriangle-district-masterplan-design-competition

(48) http://www.zaha-hadid.com/architecture/stone-towers/

(49) http://thegate.abraj-misr.com/partners/

(50) http://vincent.callebaut.org/projets-groupe-tout.html

(51) Osama Mohamed Omar: "Nanoarchitecture and Global Warming-New Revolution of Nanomaterials", Scholars' Press, 2014, Pp.162. ISBN-13:978-3-639-70975-9, ISBN10:363970975 


\title{
Architectural pattern role as a tool for design building facades in Egypt
}

\begin{abstract}
Architecture is recognized as a type of art due to its nature of harmonized compact components with each other and forming architectural pattern and physical structure. In the past, the pattern in the Egyptian buildings facades was obvious and reflects the characteristics of the environmental and social benefits. But today, these patterns have vanished and become distorted as result of successive environmental, cultural, political and social changes, which spreaded over most Egyptian cities. The result was that melted the features and aspects of local formats middle of this negative aspects, so here highlights the question: Is it possible to find a multi-functional pattern holds cultural and human features of the Egyptian society and interacts with current environmental and technological changes? What are the tools that enable the selection of a pattern to achieve commensurate with its environment and achieve effective facade with the context and the requirements of the modernism? The paper deals with the discussion of the manifestations and causes of the problem resulting from changing user requirements, and study the pattern as a concept and identify the features and role and tools devised in parallel with the study of formats Egyptian architecture environments attributes, to devise a pattern of contemporary compatible features and suggest how solutions within the framework of the lessons learned from the Egyptian environments global and local trials attributes.
\end{abstract}

Key Words:

Architecture, Pattern, Geometric, Order, parametric design, Aesthetic, structural, and environmental mitigate, traditional, fractal, Computing. 